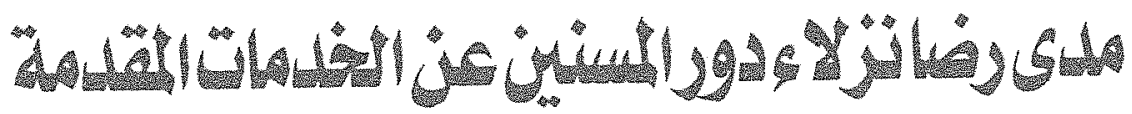

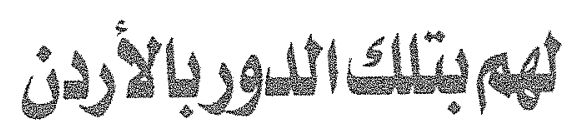

$$
\text { anc }
$$

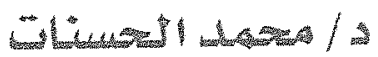




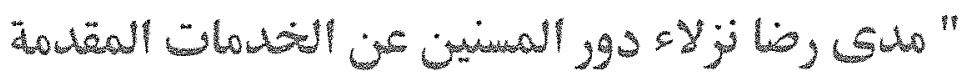

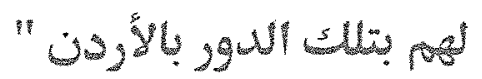

\section{* shel}

\section{Ilisurit laseo.3}

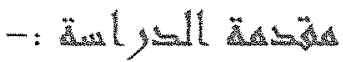

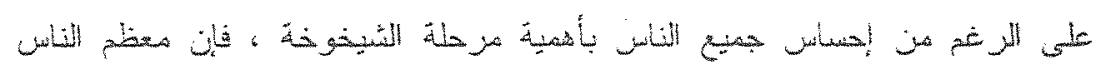

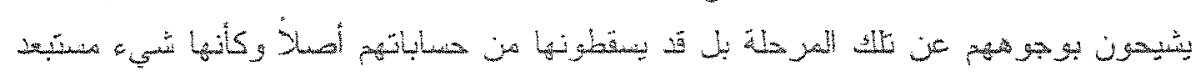

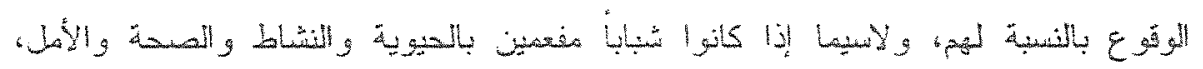

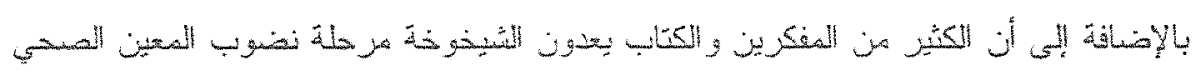

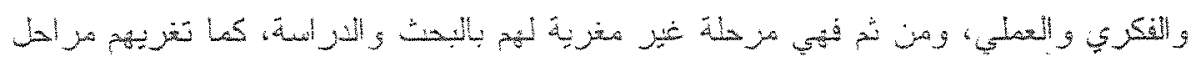

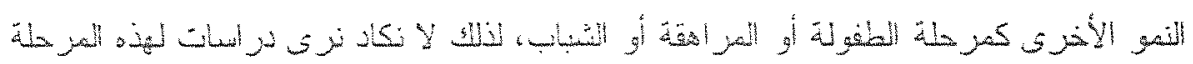

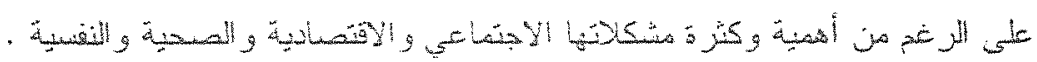

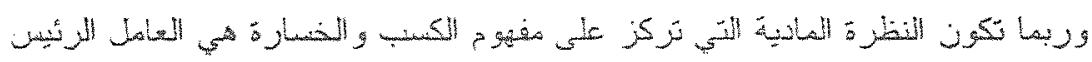

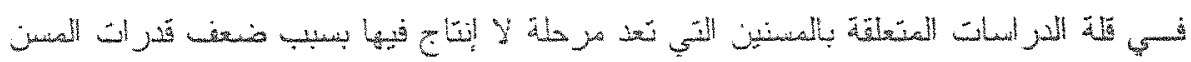

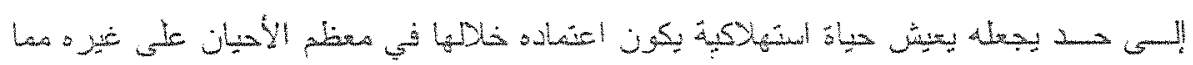

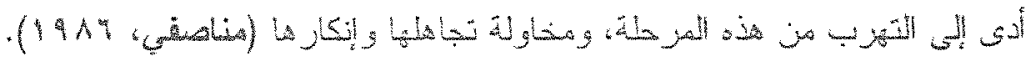

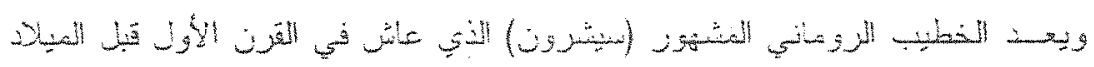

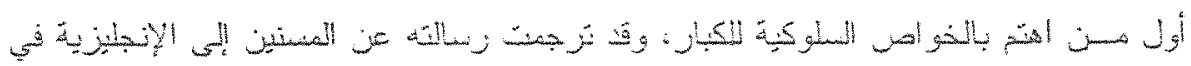

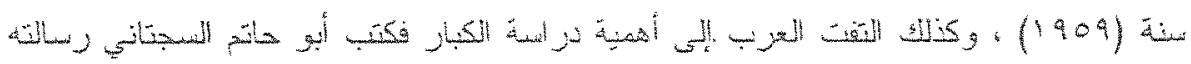

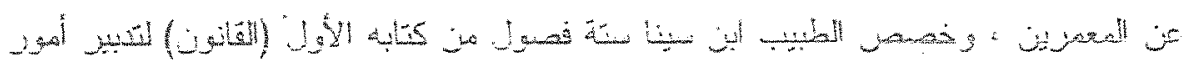

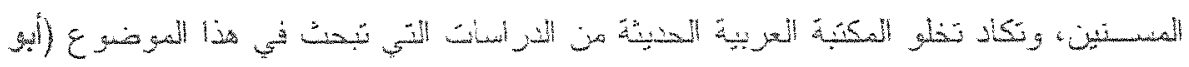

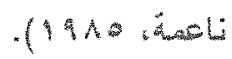

و a

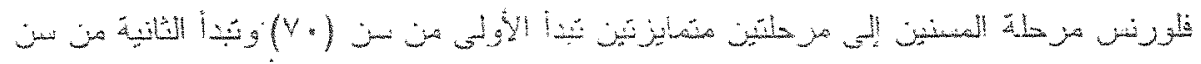




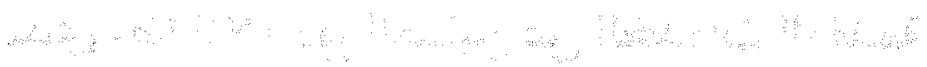

$$
2
$$

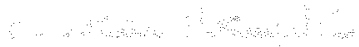

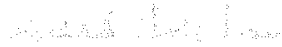

$\cdots$

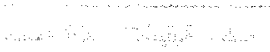




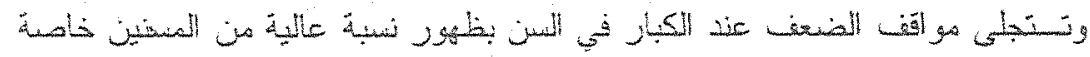

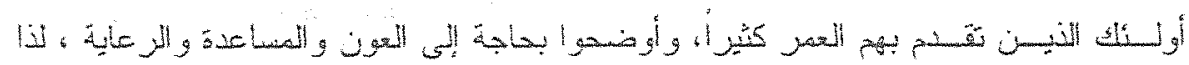

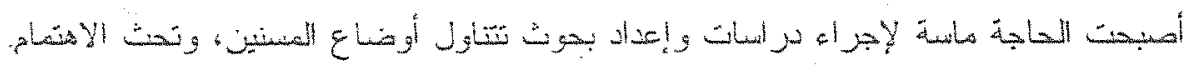

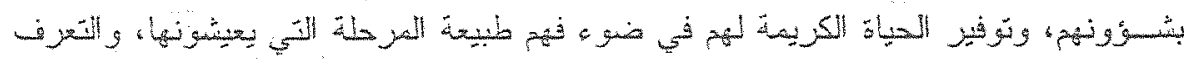

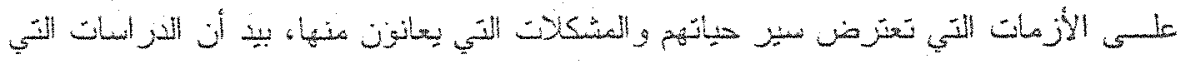

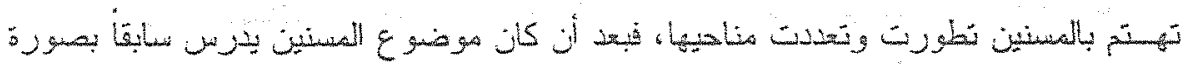

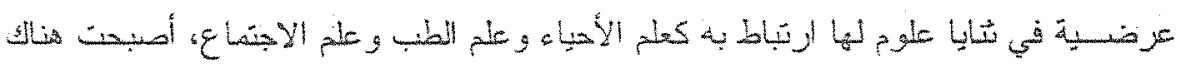

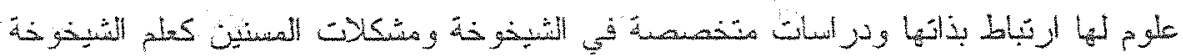

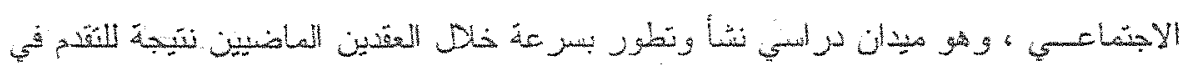

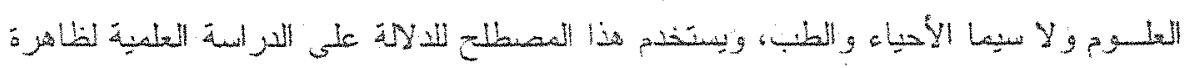

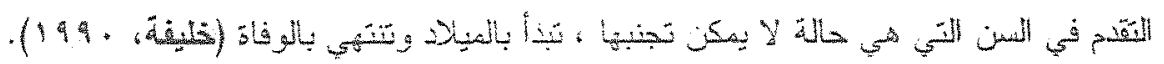

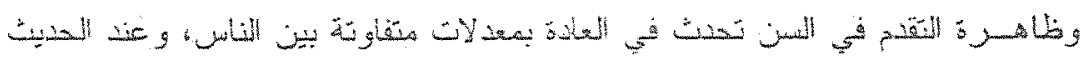

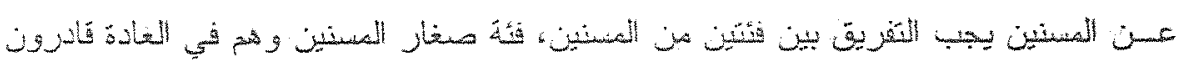

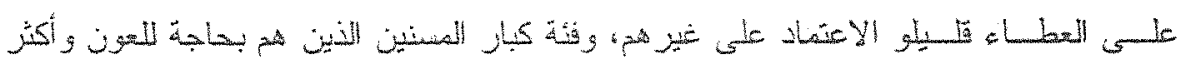

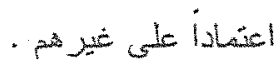

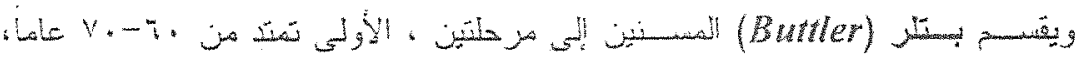

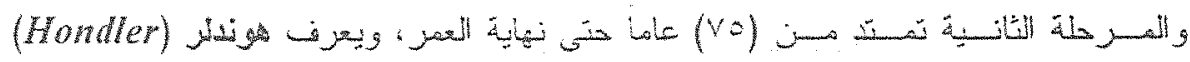

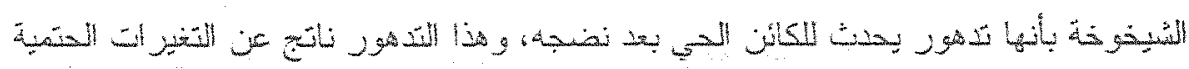

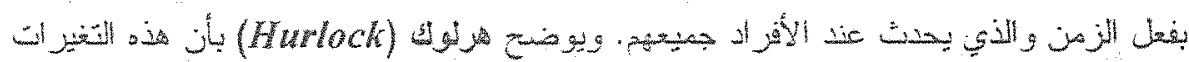

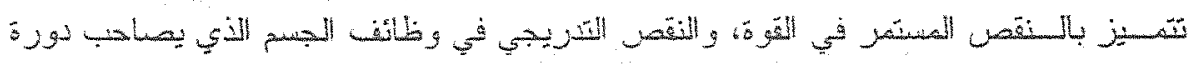

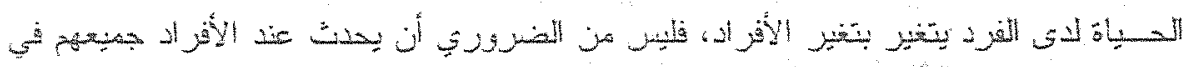

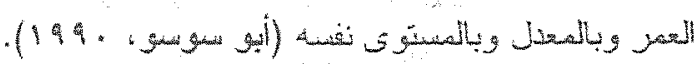

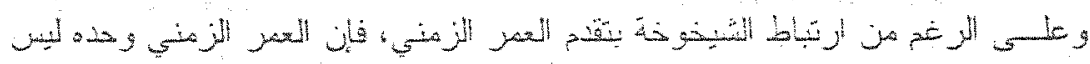

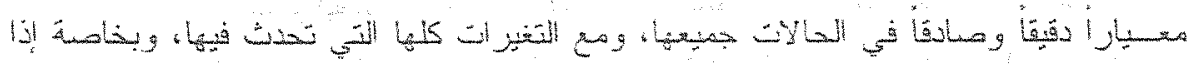

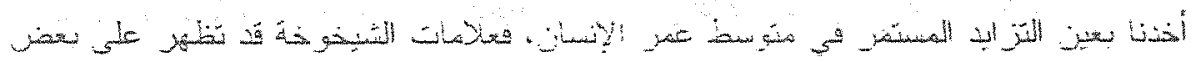

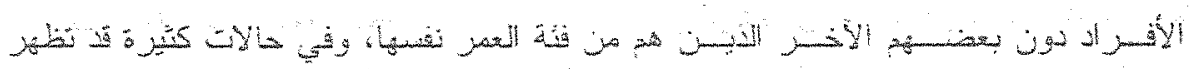

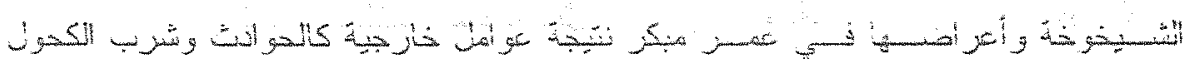

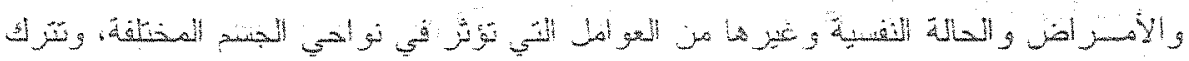


$-8+4$

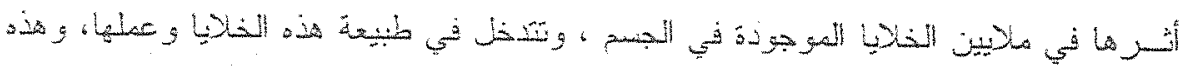

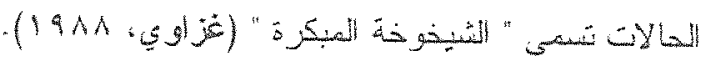

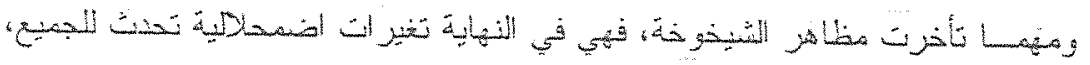

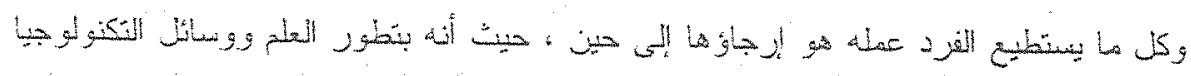

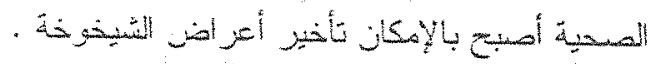

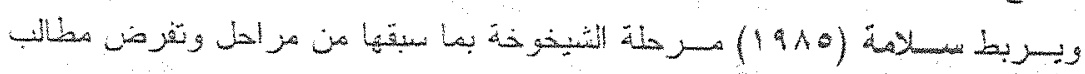

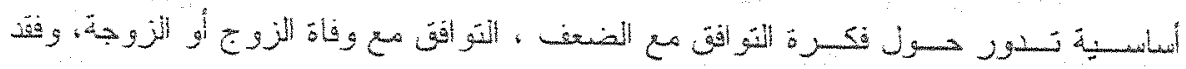

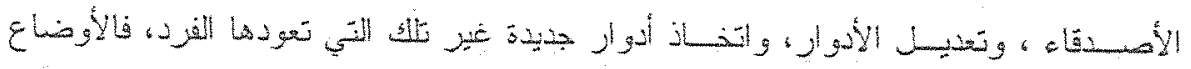

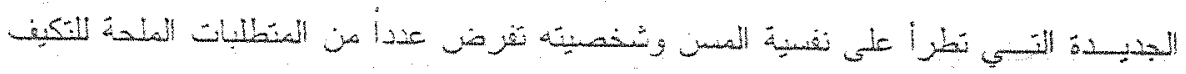

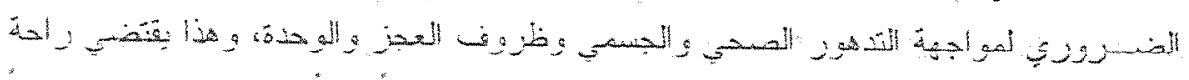

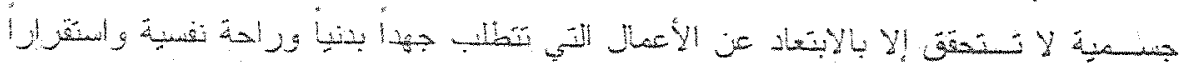

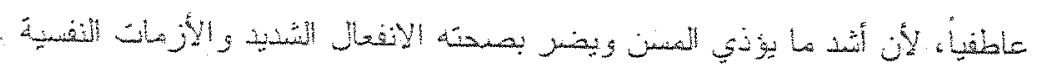

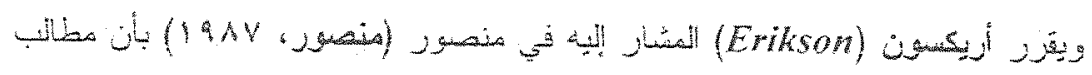

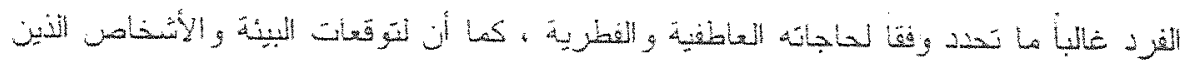

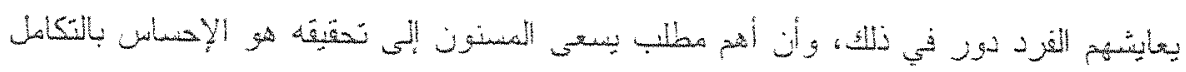

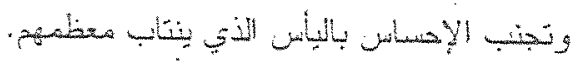

ويس

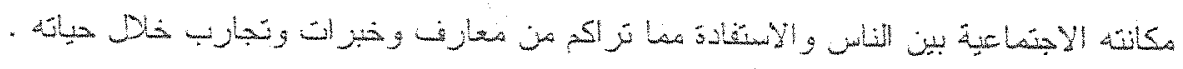

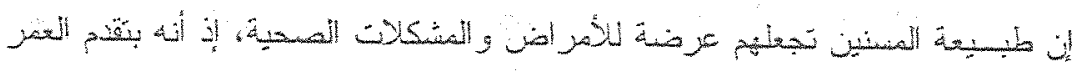

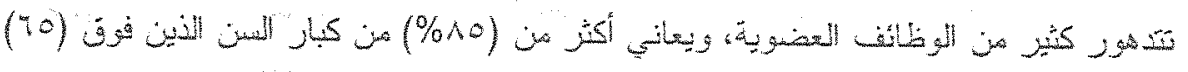

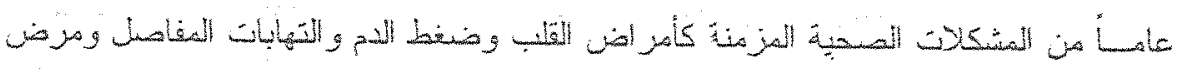

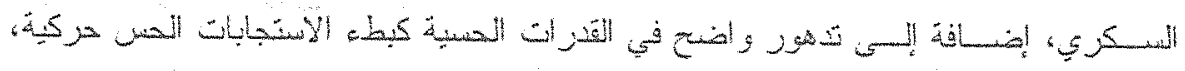

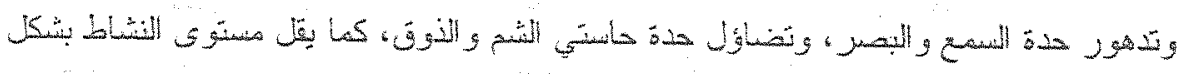

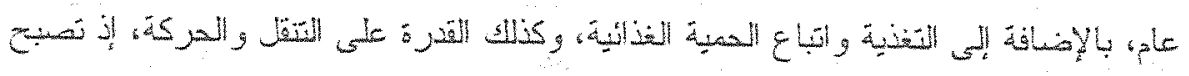

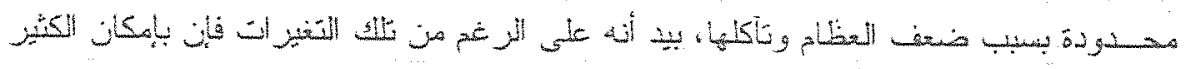

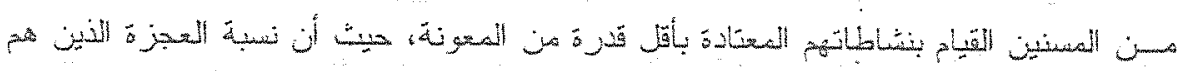

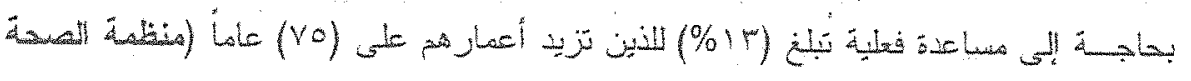




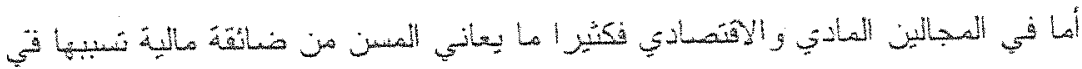

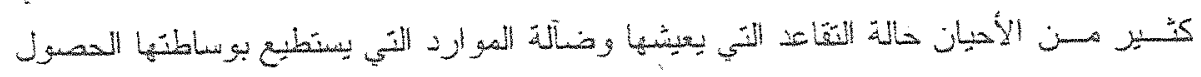

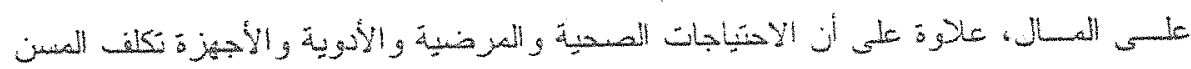

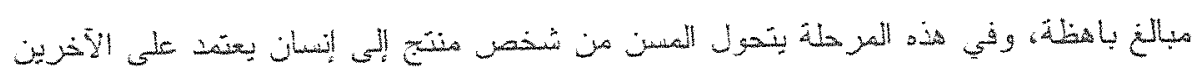

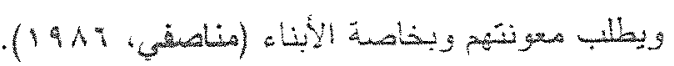

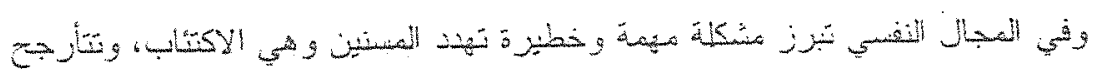

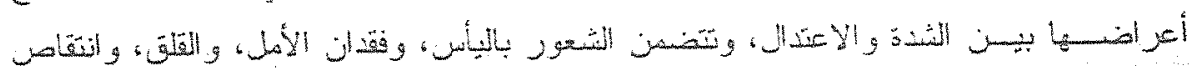

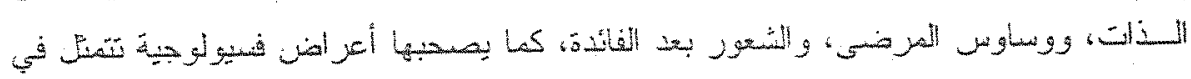

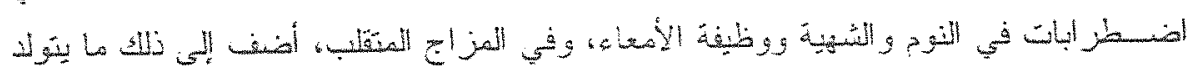

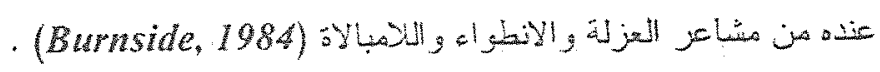

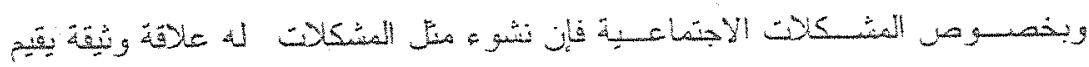

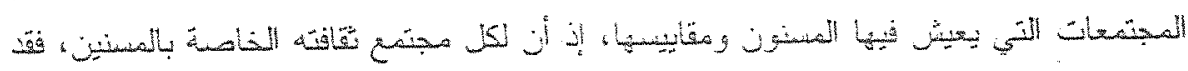

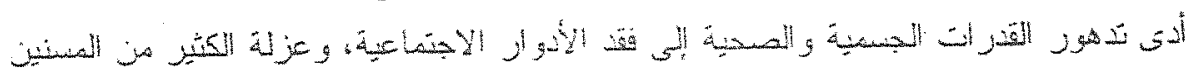

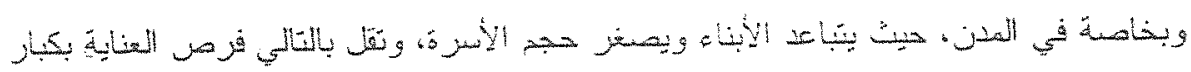

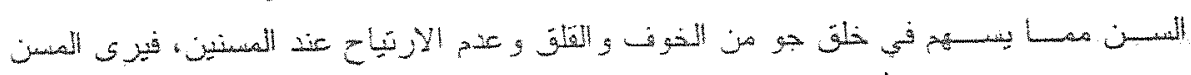

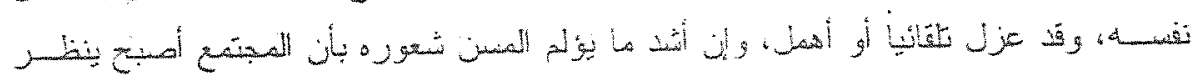

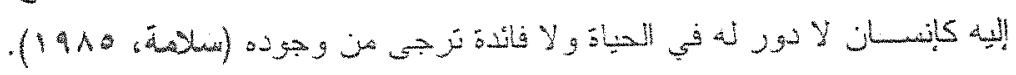

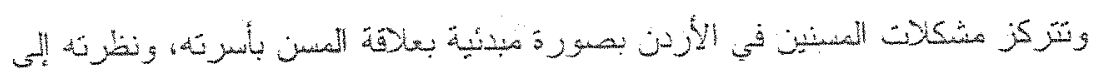

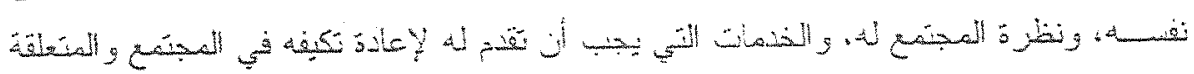

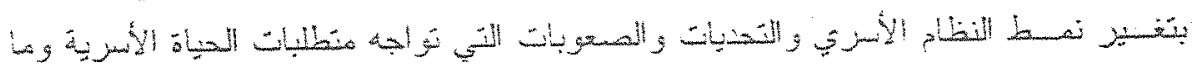

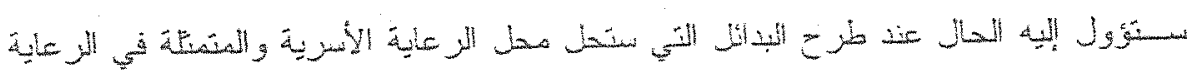

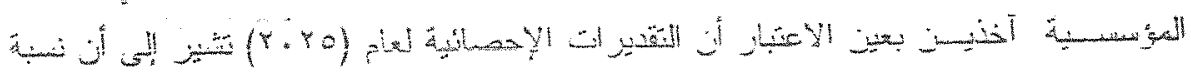

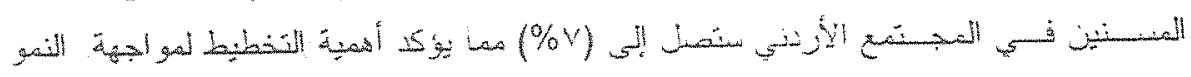

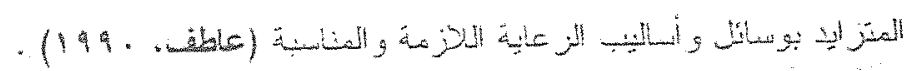

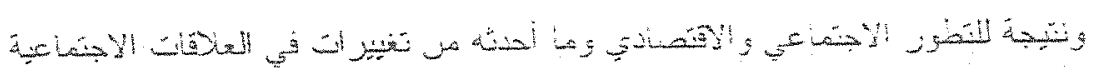

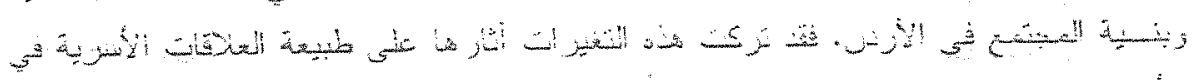

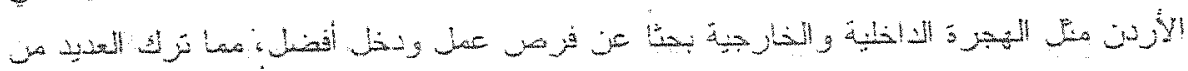

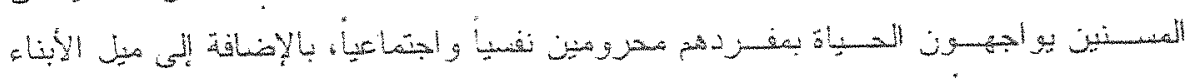

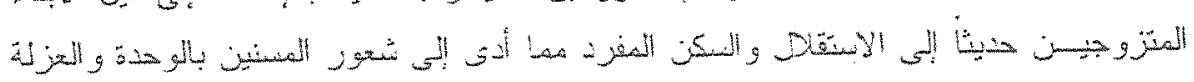




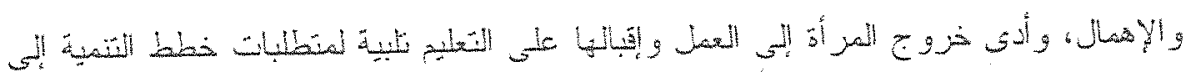

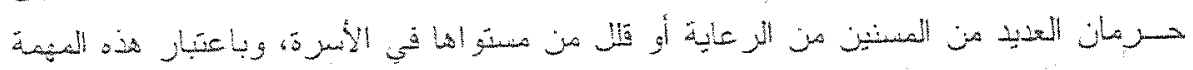

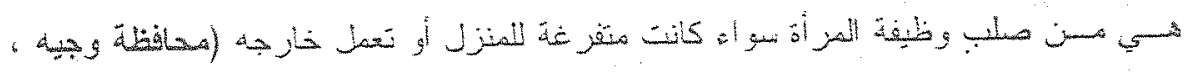

\section{- : aul}

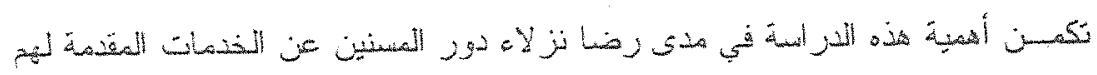

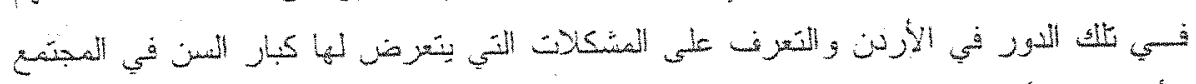

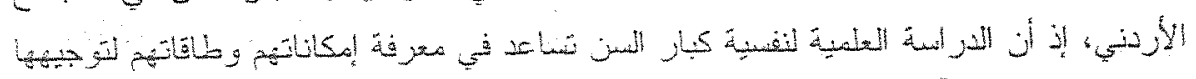

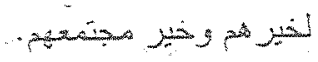

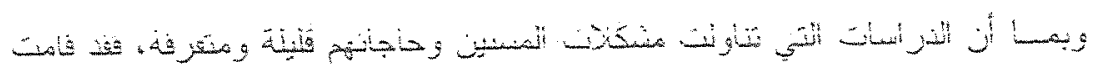

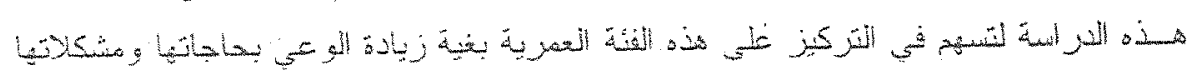

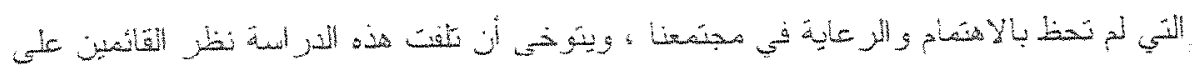

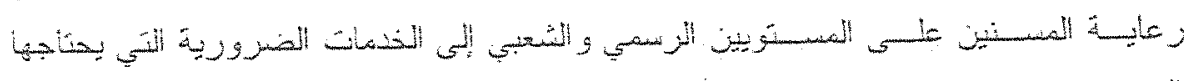

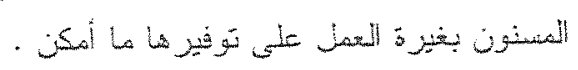

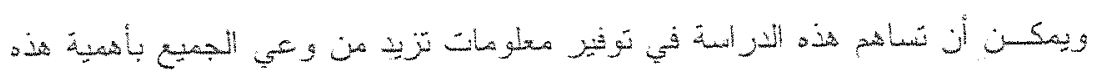

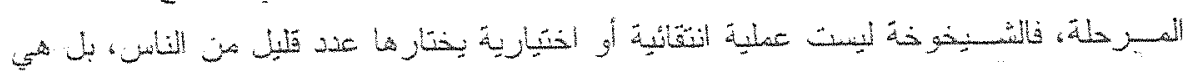

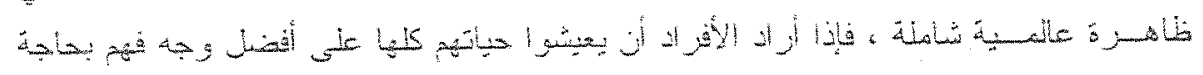

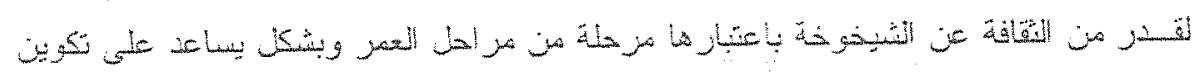

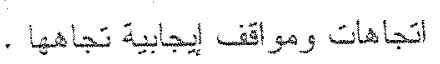

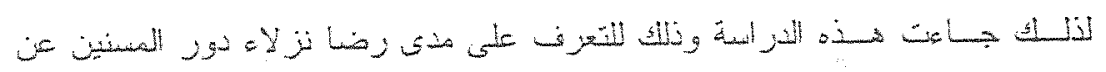

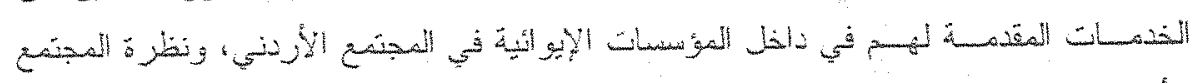

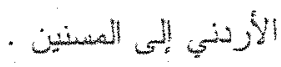

\section{- : 架新}

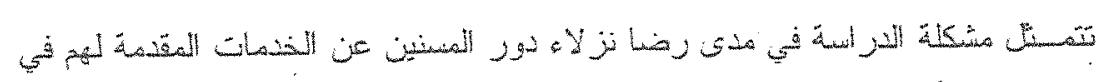

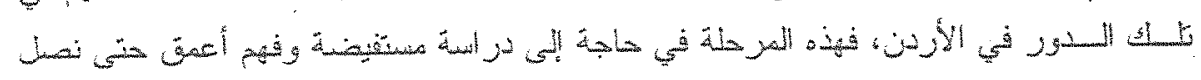

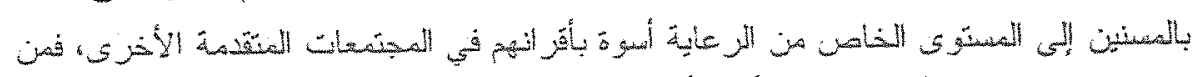

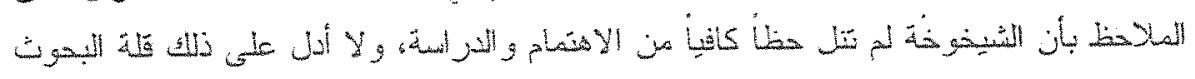




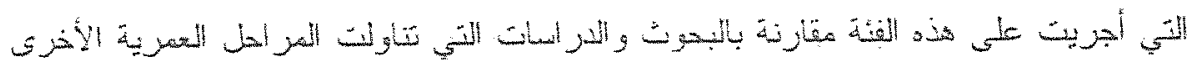
.

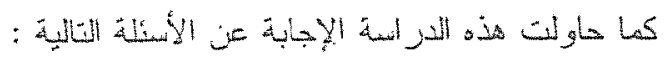

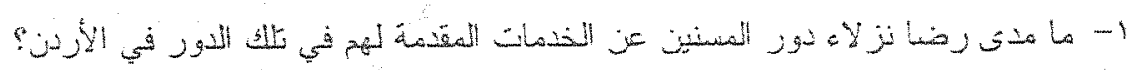

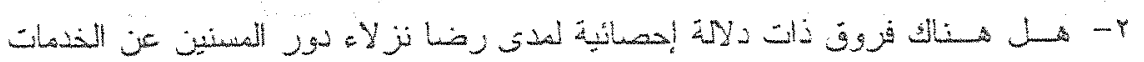

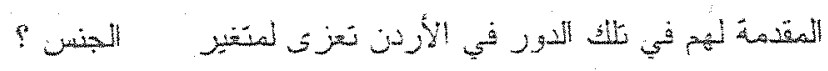

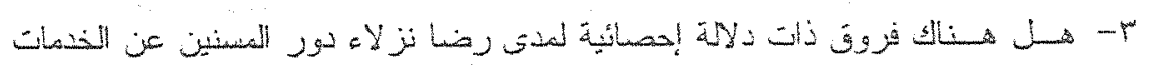

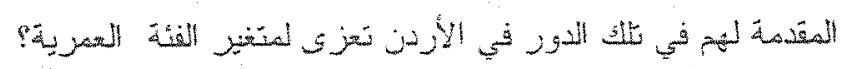

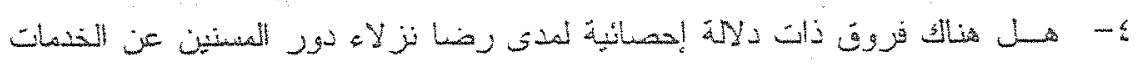

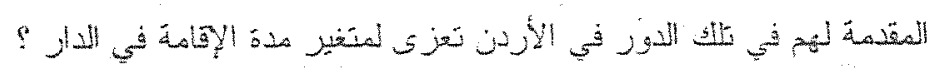

$$
\text { - : }
$$

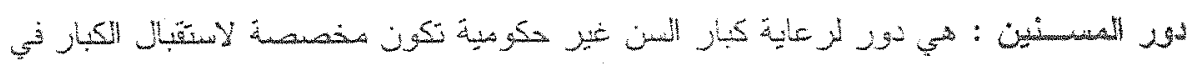

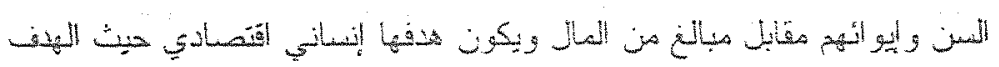

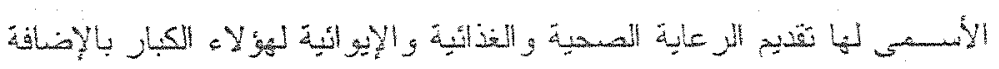

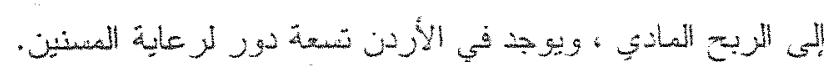

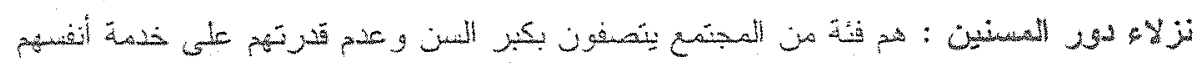

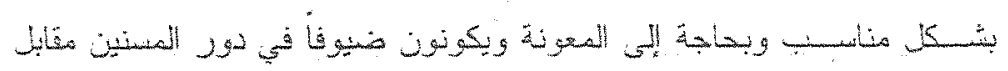

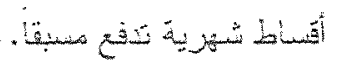

\section{- : Raj,}

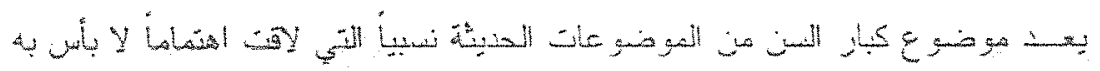

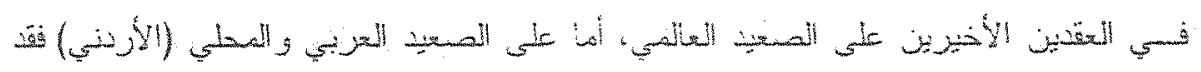

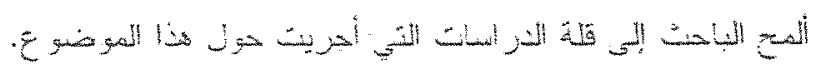

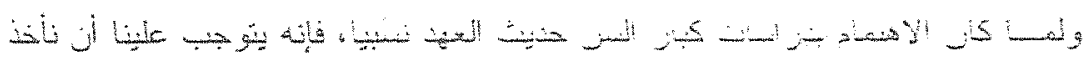

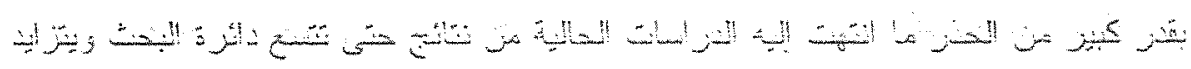

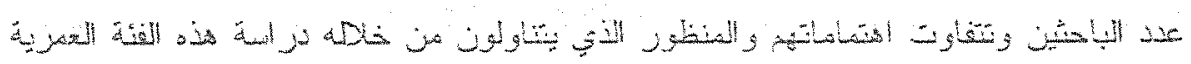




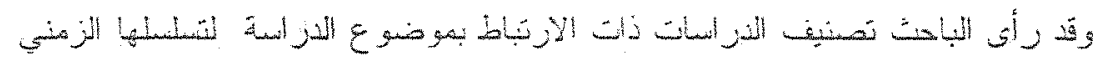

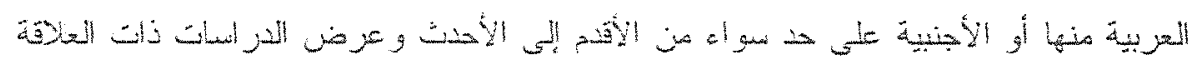

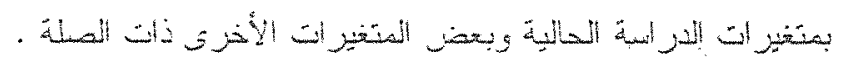

\section{- :}

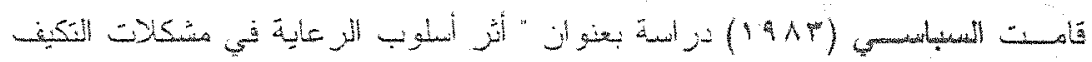

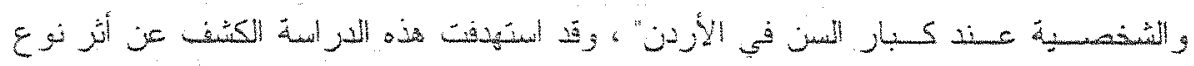

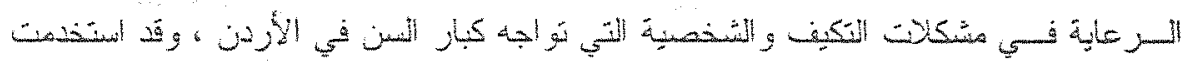

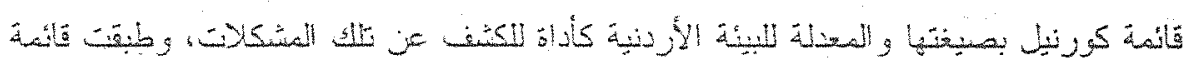

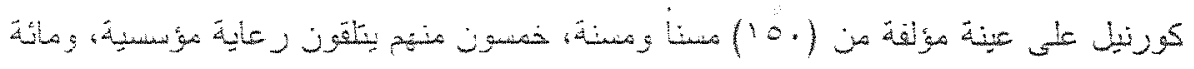

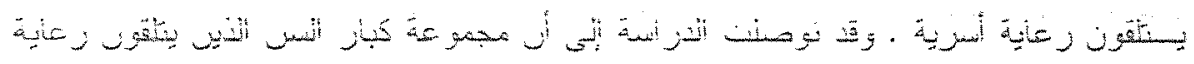

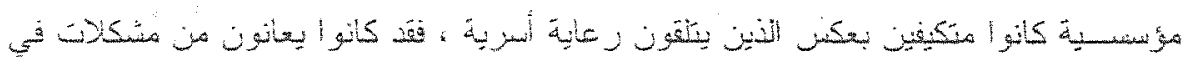

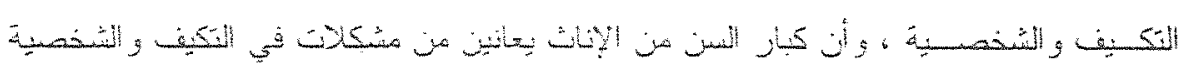

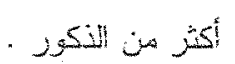

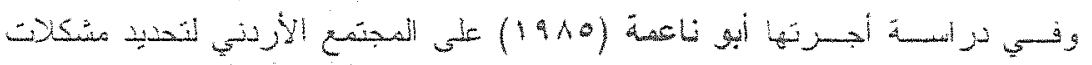

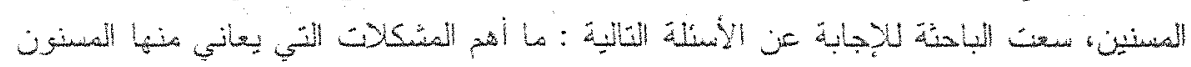

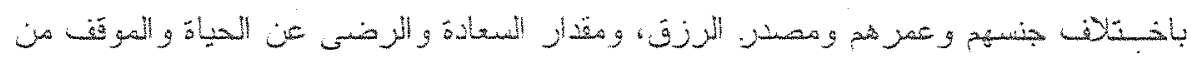

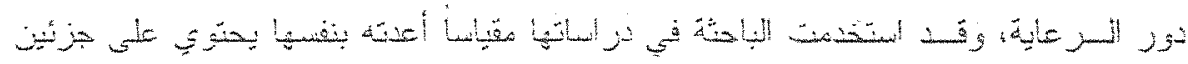

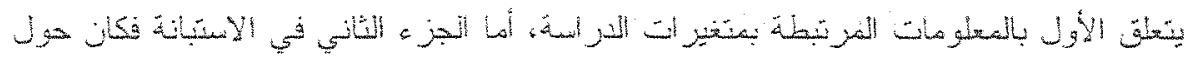

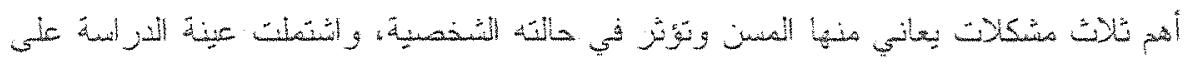

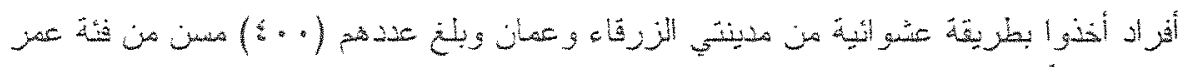

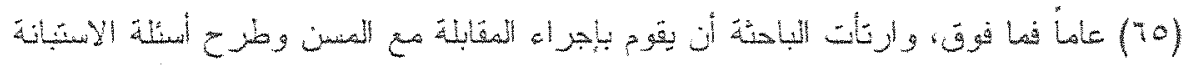

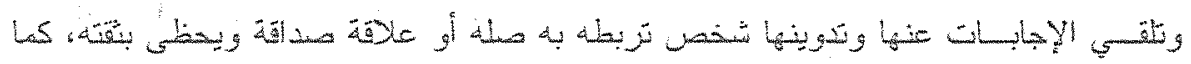

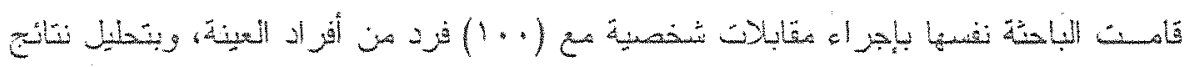

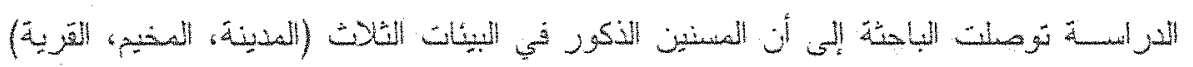

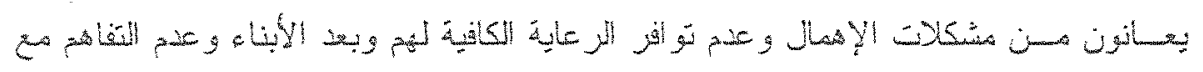

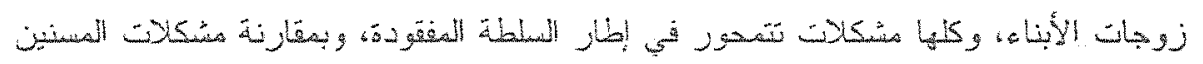

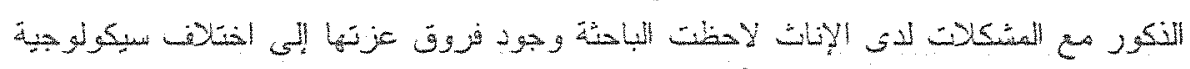

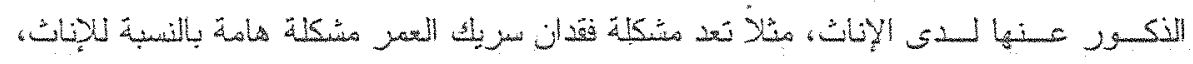

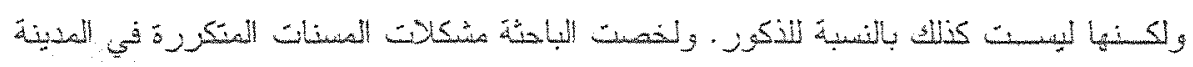

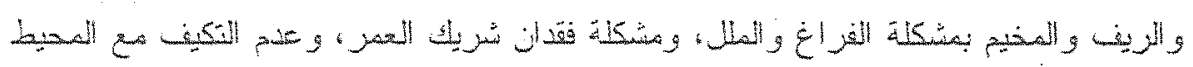




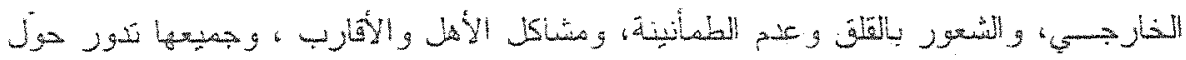

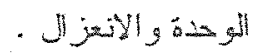

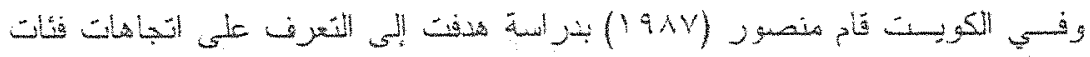

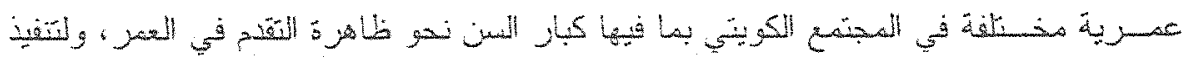

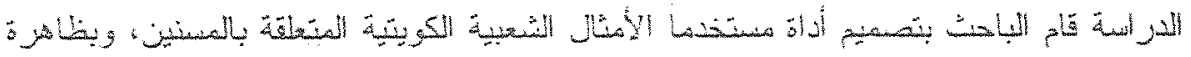

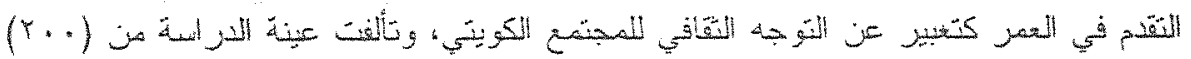

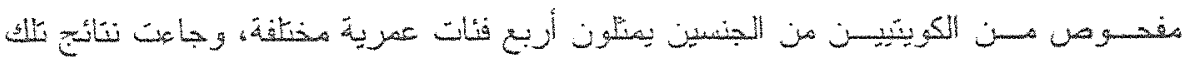

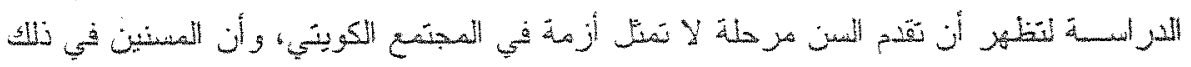

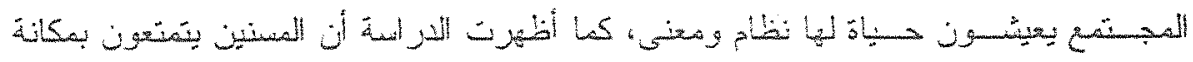

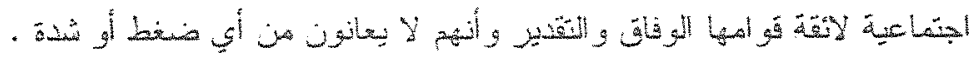

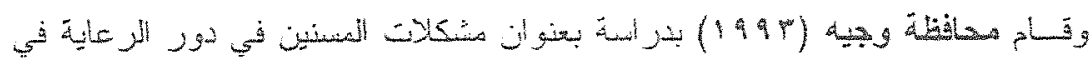

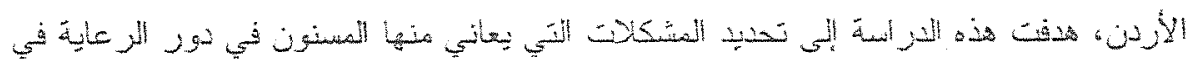

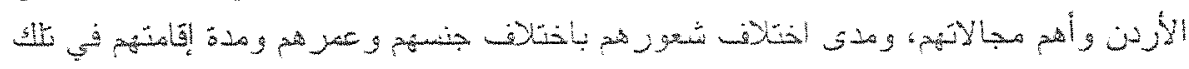

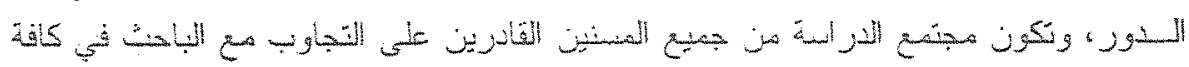

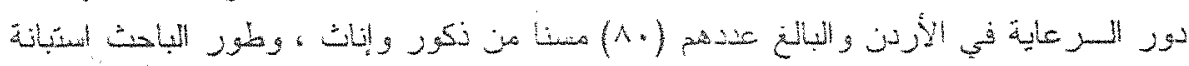

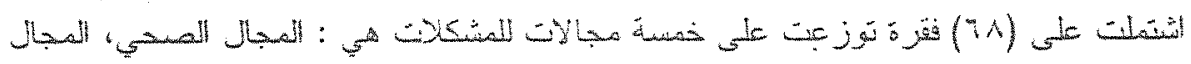

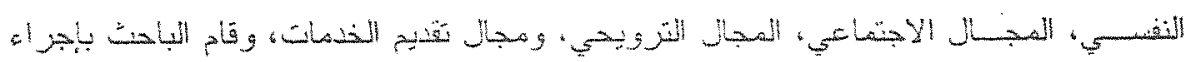

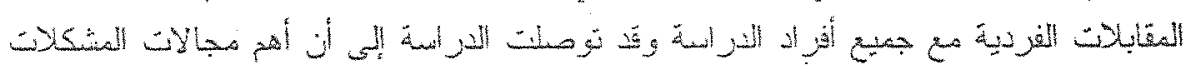

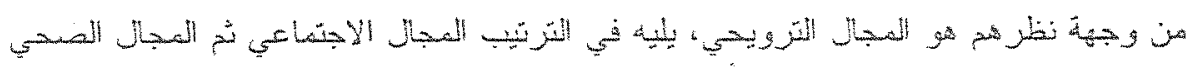

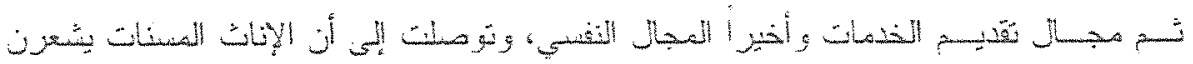

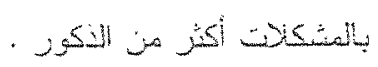

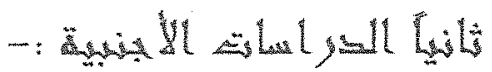

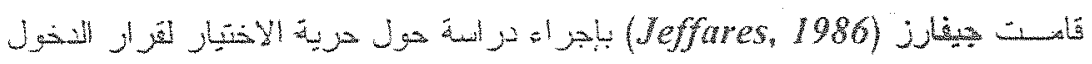

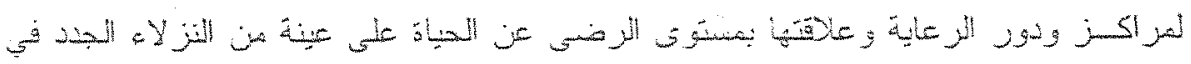

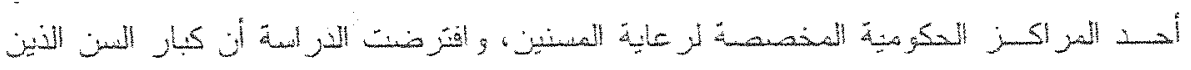

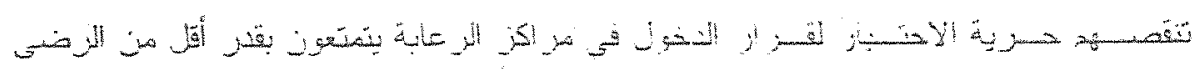

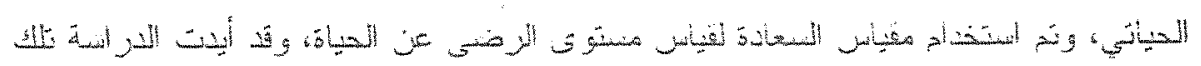

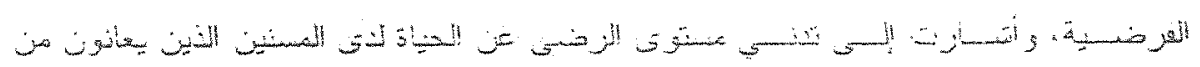

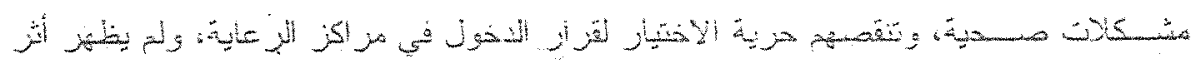

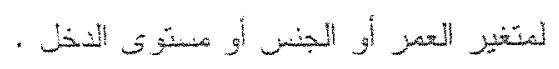




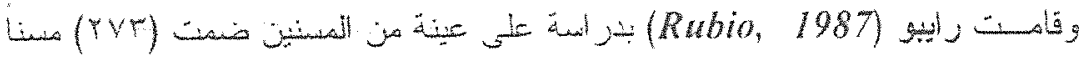

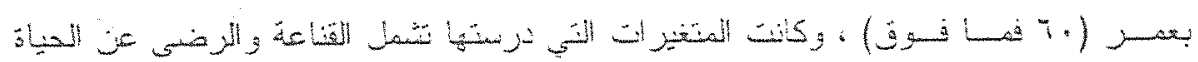

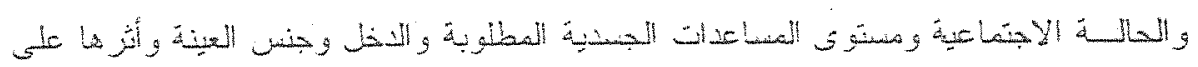

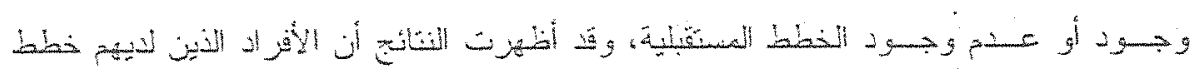

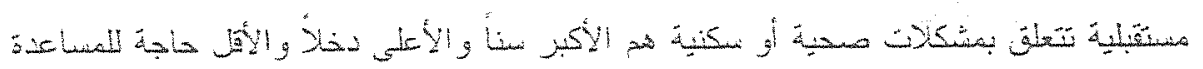
الجنسية .

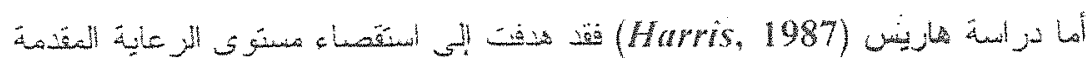

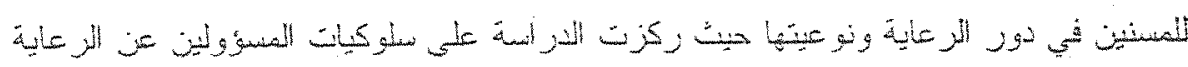

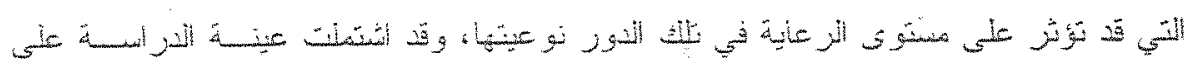

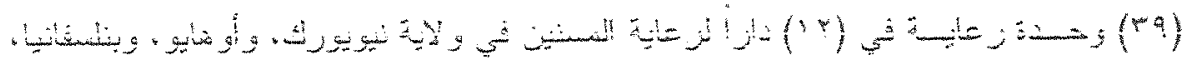

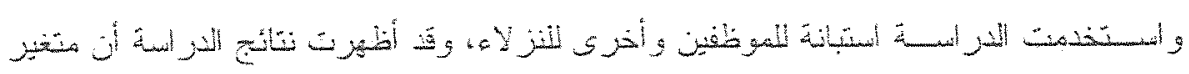

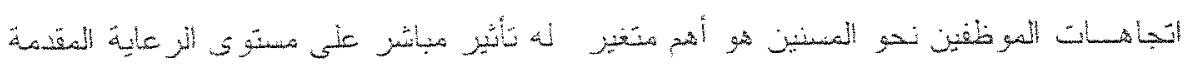
.

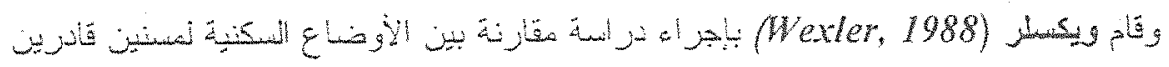

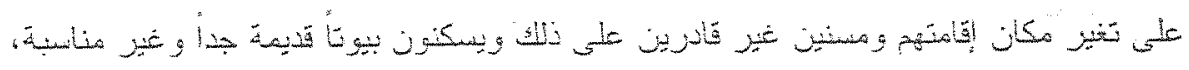

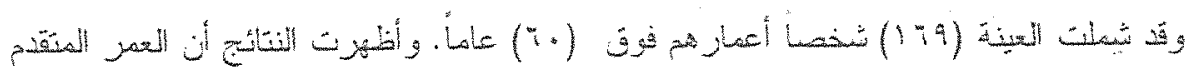

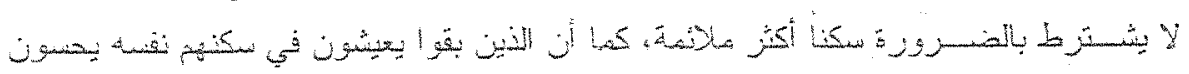

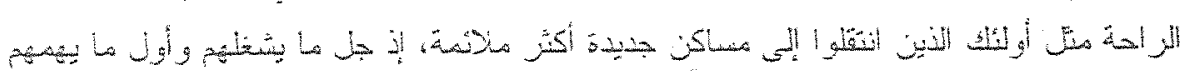

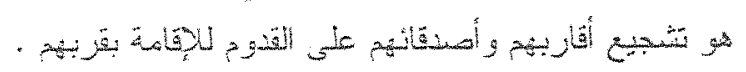

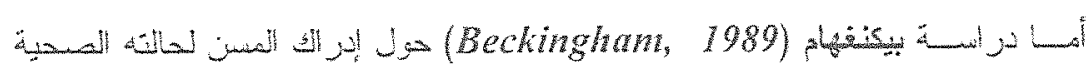

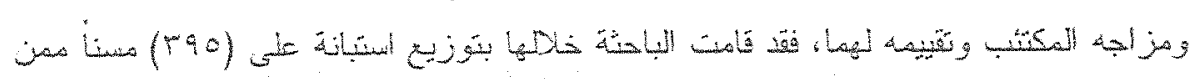

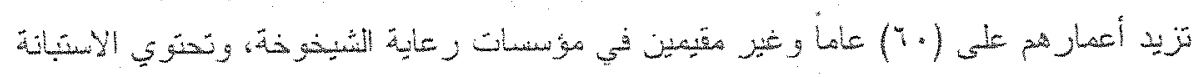

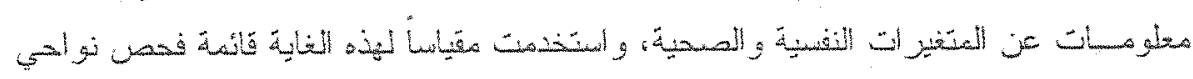

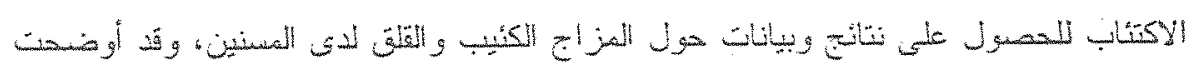

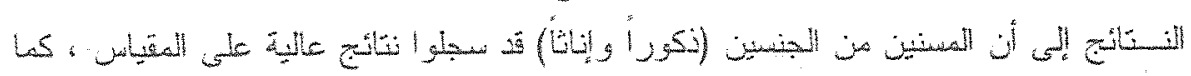

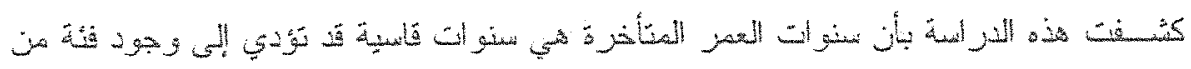

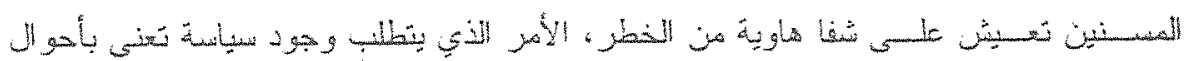

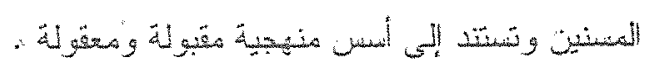




$$
\text { - : slastoll }
$$

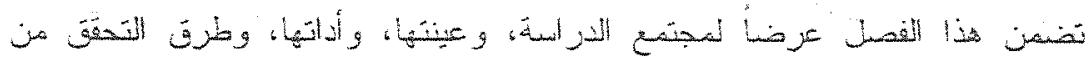

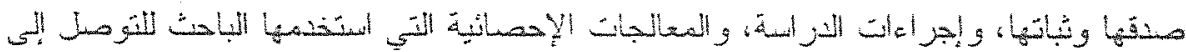
النتانئ

\section{-: 吾}

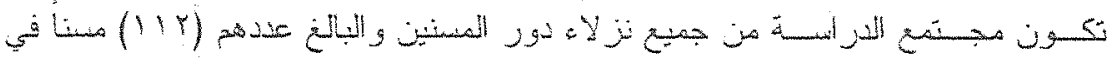

-

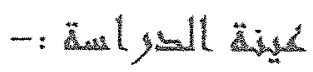

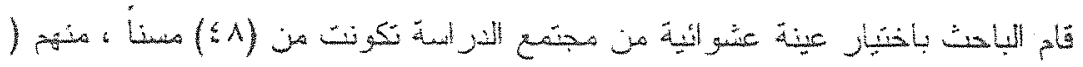

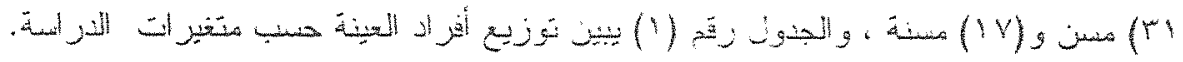

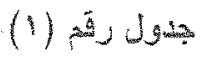

\begin{tabular}{|c|c|c|c|c|}
\hline 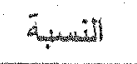 & (3) & 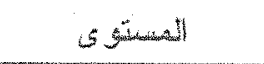 & ألsin & 墪, \\
\hline$\%: 5,7$ & $r$ & 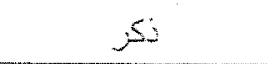 & \multirow{2}{*}{ إنس } & \multirow{2}{*}{$!$} \\
\hline$\%+0,5$ & iv & أنَن & & \\
\hline$\%$ & v & 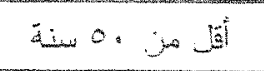 & \multirow{3}{*}{ القفئ المعربية } & \multirow{3}{*}{ Y } \\
\hline$\%+9,4$ & 19 & 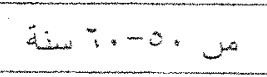 & & \\
\hline$\%: 0, \wedge$ & ry & $=-i-j$ & & \\
\hline$\%: \gamma, q$ & $r$ & 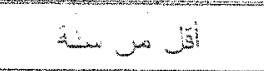 & \multirow{3}{*}{ 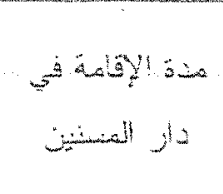 } & \multirow{3}{*}{ F } \\
\hline$\%+r$ & 10 & $E-\cdots$ & & \\
\hline$\% r \cdot, \lambda$ & 1. & أ & & \\
\hline
\end{tabular}

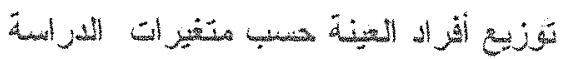




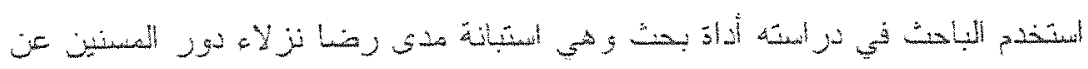

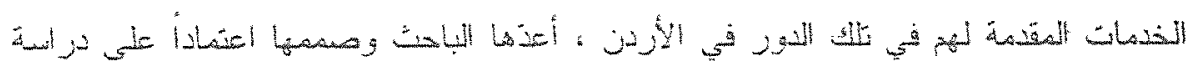

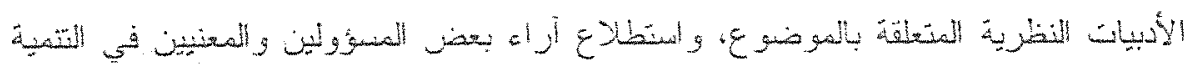

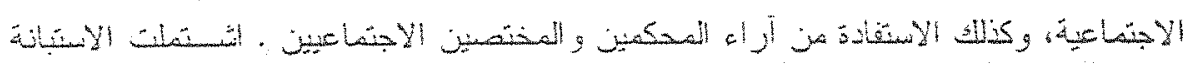

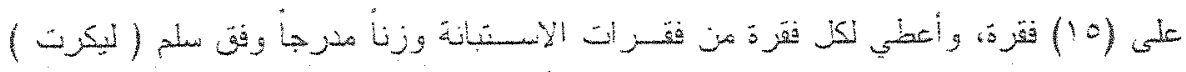

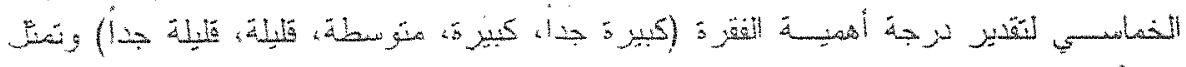

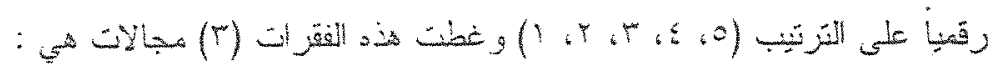

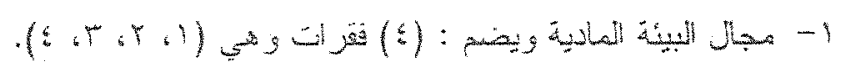

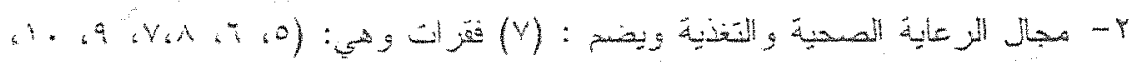

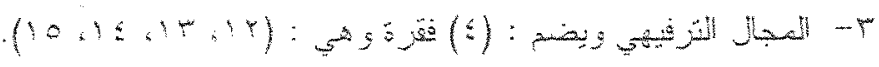

$$
\begin{aligned}
& \text { - : ثان }
\end{aligned}
$$

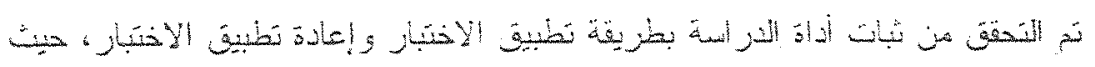

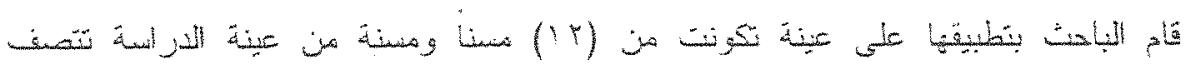

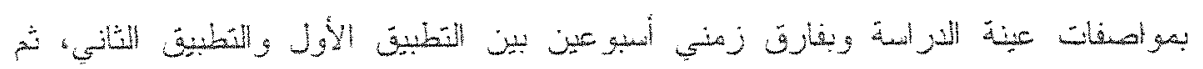

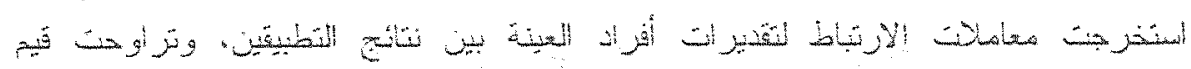

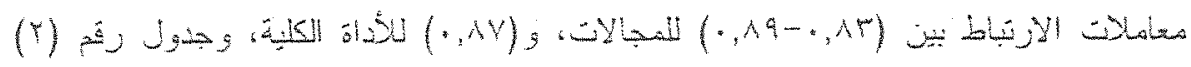

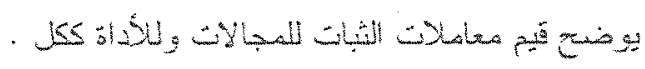

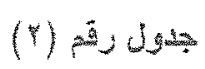

\begin{tabular}{|c|c|c|c|}
\hline هـل يلثبات & St & المجال & 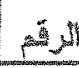 \\
\hline$\cdot, \wedge 9$ & $\leqslant$ & هبال البيئة المادية & 1 \\
\hline$\therefore A r$ & $v$ & مجال الر عاية الصحية و التغنية & r \\
\hline$\therefore, 10$ & $\xi$ & 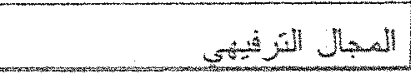 & $r$ \\
\hline$\cdot, A V$ & 10 & 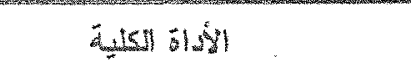 & \\
\hline
\end{tabular}

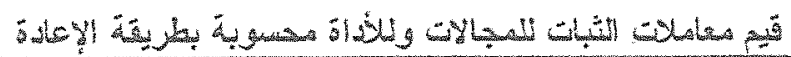




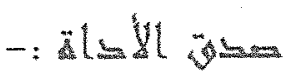

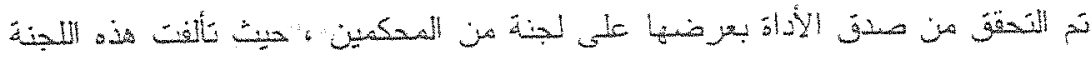

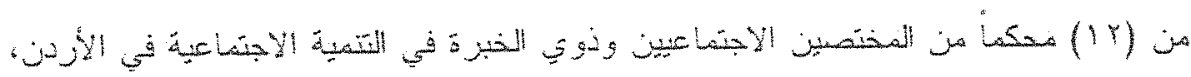

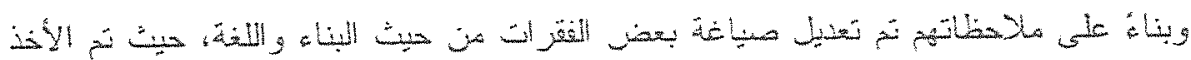

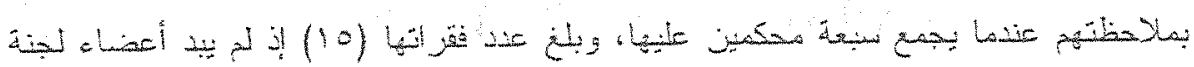

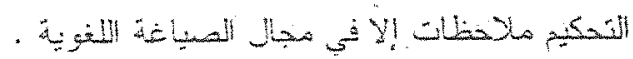

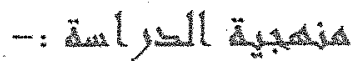

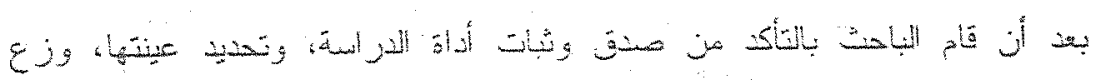

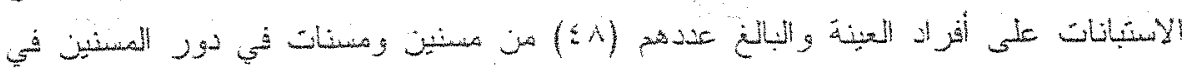

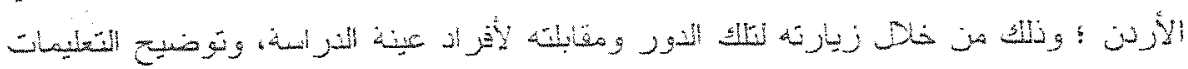

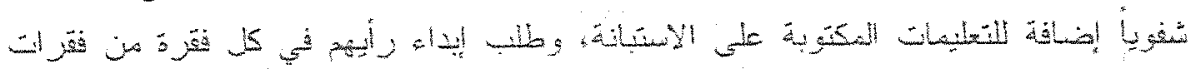

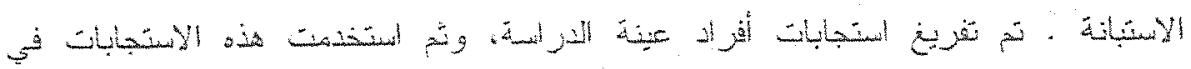
. $-:$ :

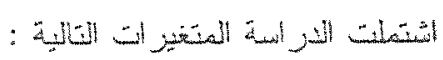

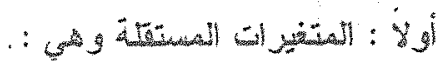

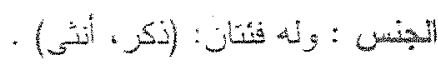

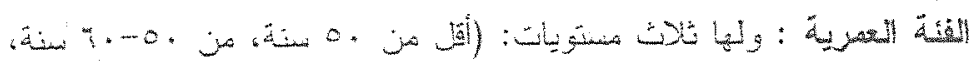

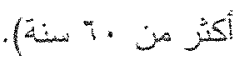

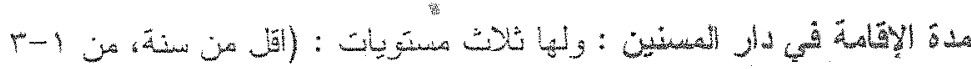

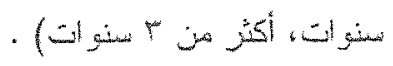

:

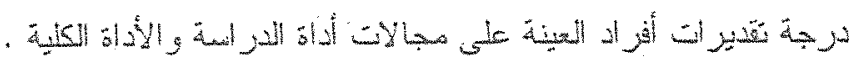

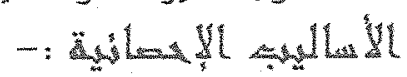

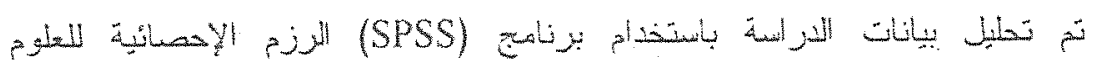
الاجنسية

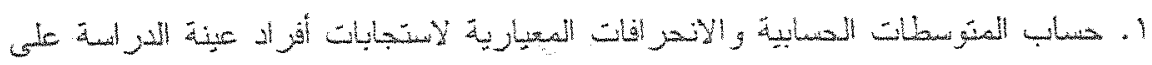
ألداة اللز أسة .

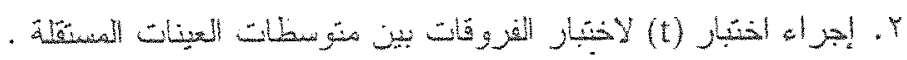




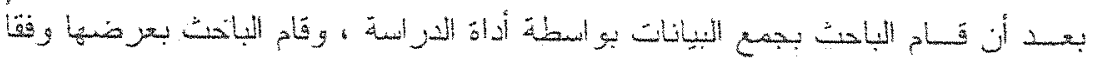

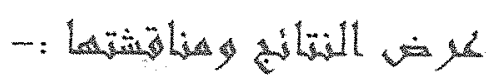

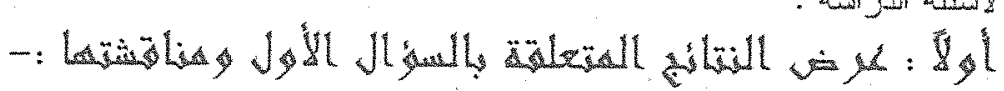

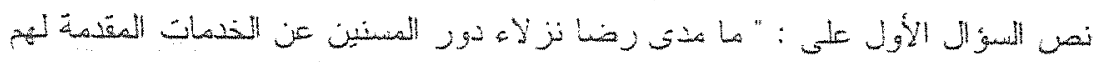

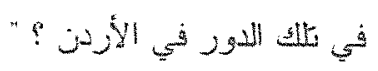

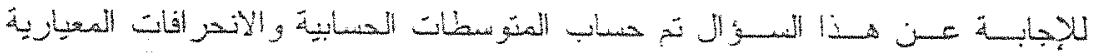

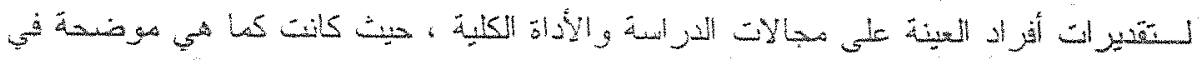

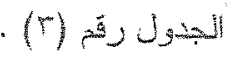

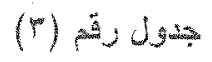

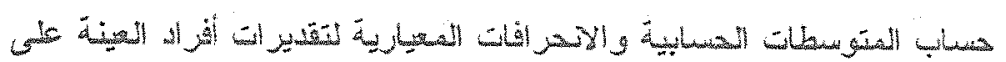

\begin{tabular}{|c|c|c|c|c|}
\hline المنتبة & الائنديال & المستوبي" & المجبال & اللزقتم \\
\hline الأولى & $:, V \leq$ & $5,1 \mathrm{~V}$ & مجال البيئة الماندية & 1 \\
\hline الثالثة & $\cdot, \leq 4$ & $Y, A=$ & مجال الل عاية المسيث و التنتية & Y \\
\hline 吾 & $\because, V Y$ & $5,1 \%$ & 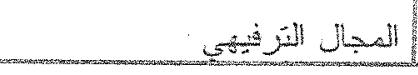 & $r$ \\
\hline- & $\therefore \leqslant 0$ & $r, r \wedge$ & 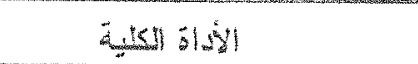 & \\
\hline
\end{tabular}

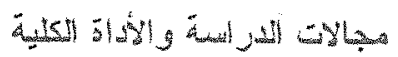

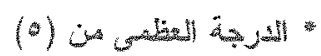

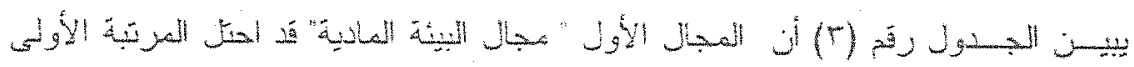

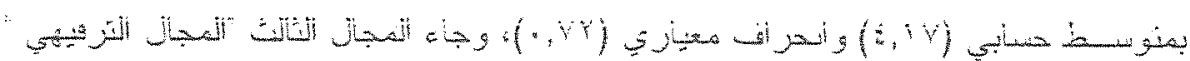

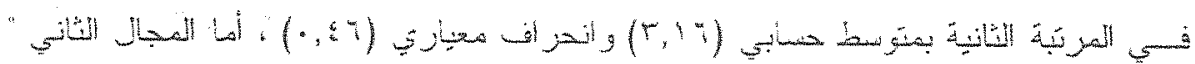

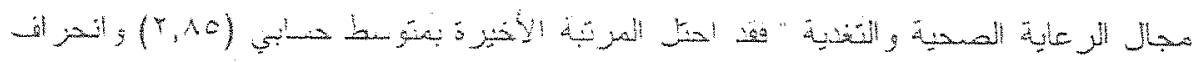

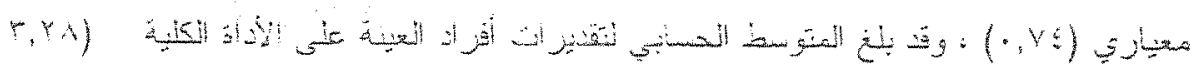

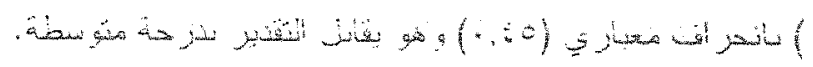

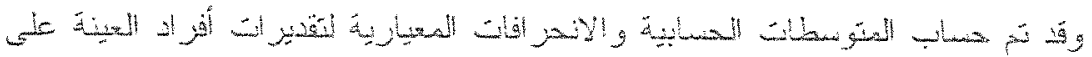

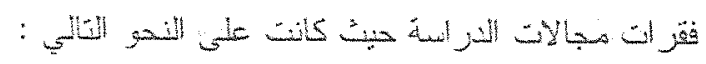

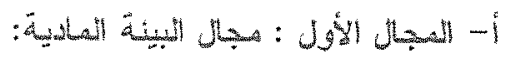




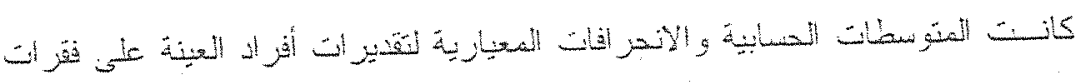

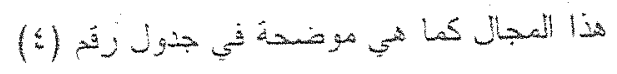

(6) 3,30

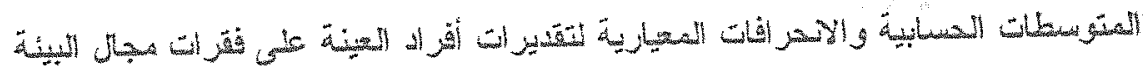
aيdust

\begin{tabular}{|c|c|c|c|c|}
\hline 运 & sylut & Livadis & 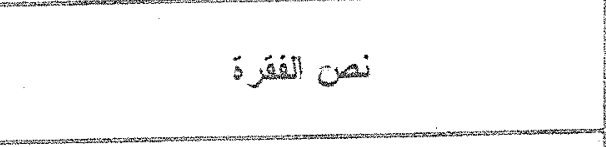 & ال \\
\hline أنية & $\because 189$ & $5, Y D$ & 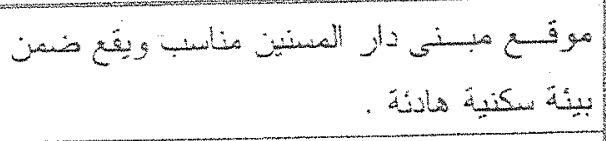 & $\uparrow$ \\
\hline-1921 & $\because A Y$ & $\therefore, r V$ & 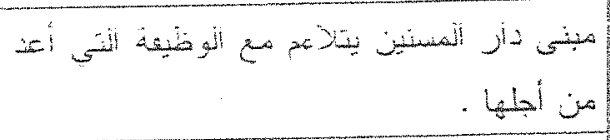 & $Y$ \\
\hline الز أبية" & $\because A$ & $r, 96$ & 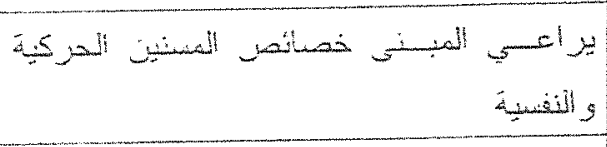 & $r$ \\
\hline ¿illi & $=, v r$ & 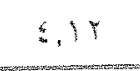 & 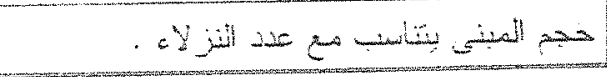 & $\leqslant$ \\
\hline- &.,$Y \leqslant$ & $5,1 v$ & JSs jeanl & \\
\hline
\end{tabular}

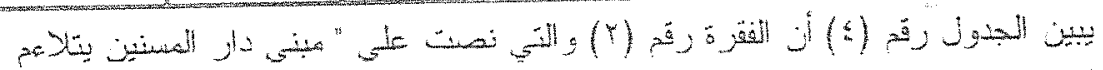

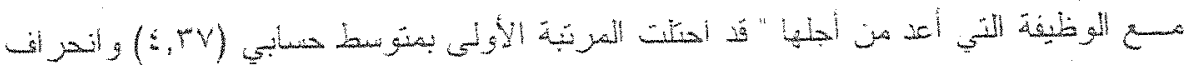

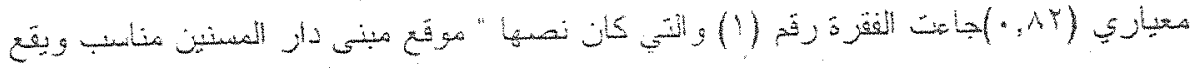

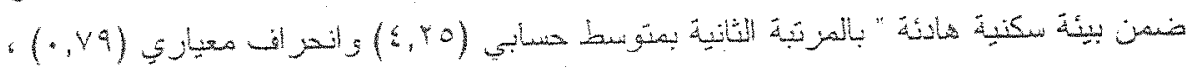

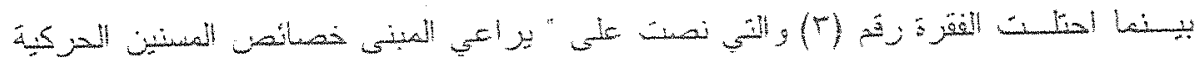

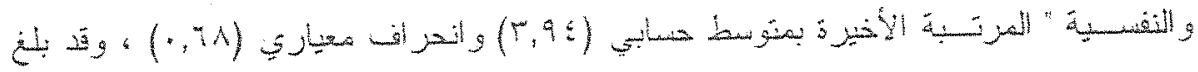

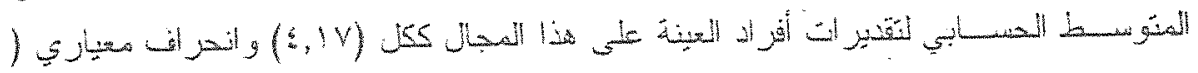

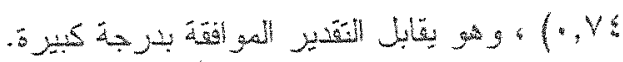
:

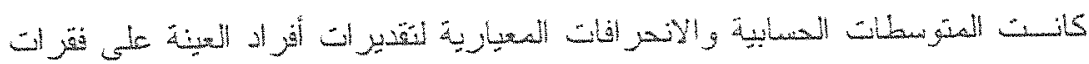

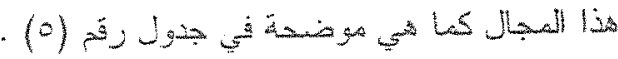




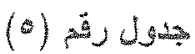

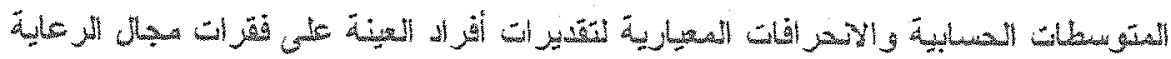
الإسية و التغنية

\begin{tabular}{|c|c|c|c|c|}
\hline اللزة & 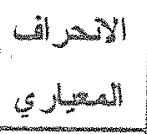 & 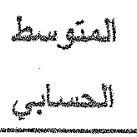 & تَ & 离嵌 \\
\hline BU] & .7. & $r, ! \leqslant$ & 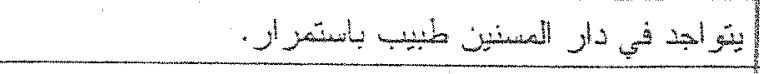 & $\circ$ \\
\hline 4 & $\therefore, A Y$ & $r, Y$ & 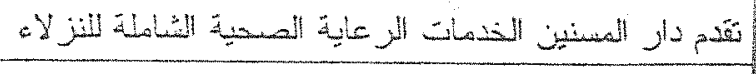 & $i$ \\
\hline | & $.9 Y$ & $r \cdot 1$ & 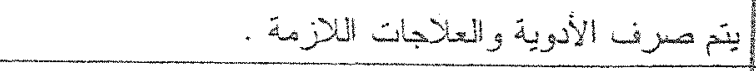 & v \\
\hline$y$ & $\cdot, \lambda \leqslant$ & r, & 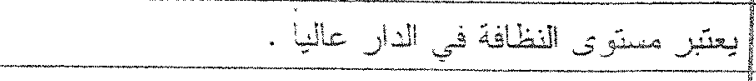 & $A$ \\
\hline LII & $\cdot, \lambda$ & $Y, A$ & 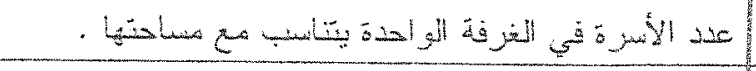 & 9 \\
\hline أل & $*, \forall A$ & $Y,+1$ & 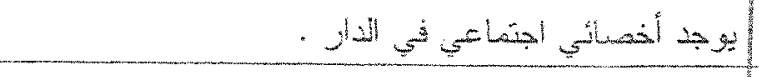 & 1 \\
\hline \multirow[t]{2}{*}{ 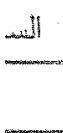 } &., $9 !$ & $r, * 0$ & 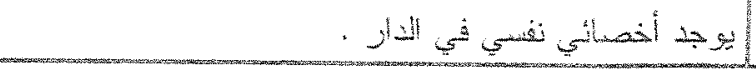 & 11 \\
\hline & $\cdot, \leqslant$ & $Y, \lambda 0$ & US Jlandil & \\
\hline
\end{tabular}

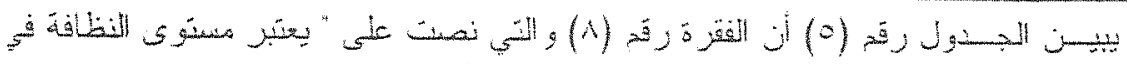

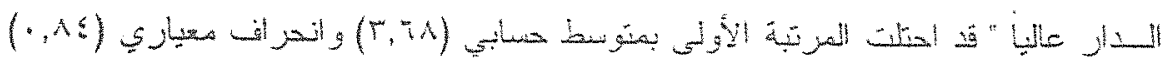

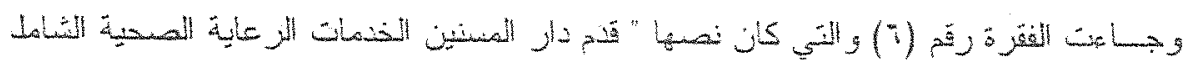

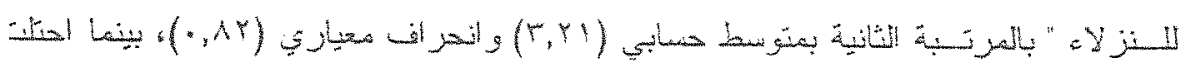

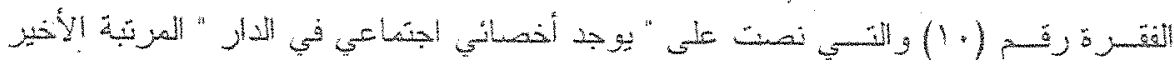

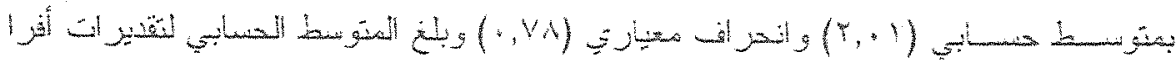

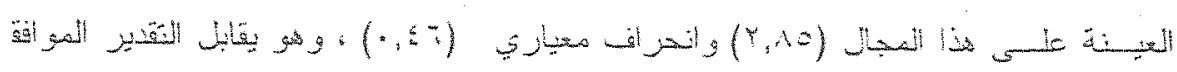
بنزجة هتونسطة.

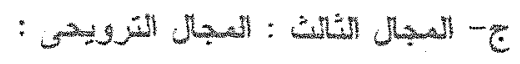

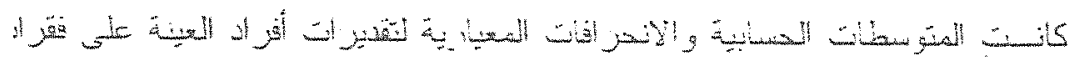

$$
\text { (i) (i) }
$$




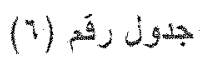

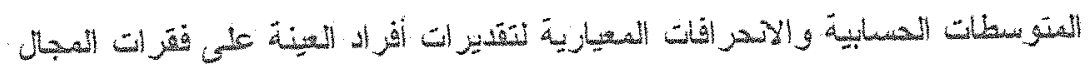

\begin{tabular}{|c|c|c|c|c|}
\hline الزيتبة & |لمبيان & المتوسيط & نصل الفترة & اللرئم \\
\hline 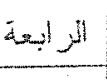 & $\therefore 95$ & $r, 11$ & 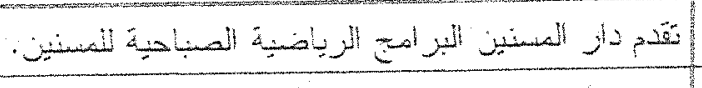 & 'r \\
\hline الثبانة & $\because A$ & Y,OV & 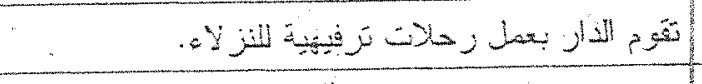 & 14 \\
\hline $\operatorname{sig}$ & $\therefore, \Lambda$ & 5,74 & 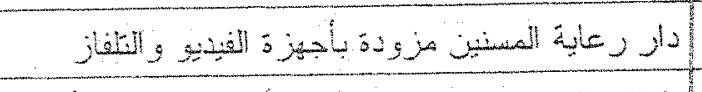 & $1 \leqslant$ \\
\hline النقانية & $\therefore, 19$ & $r, r$ & 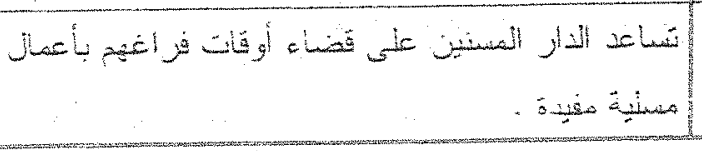 & 10 \\
\hline - & $\cdot, V Y$ & $5: 4$ & الئمبs & \\
\hline
\end{tabular}

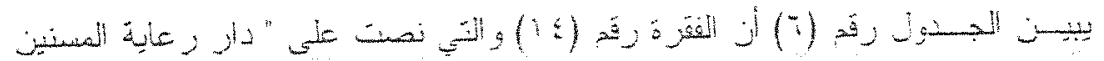

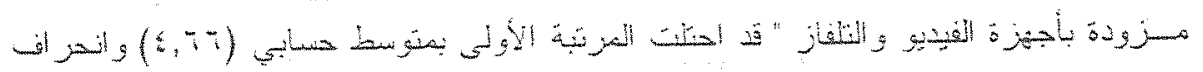

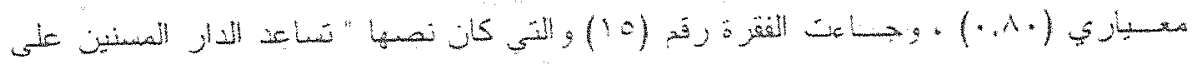

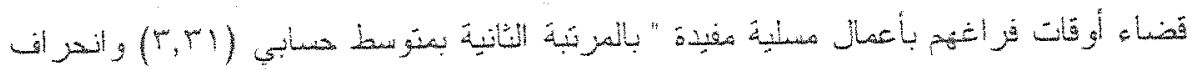

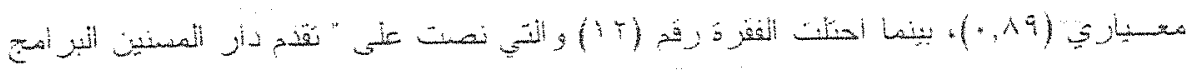

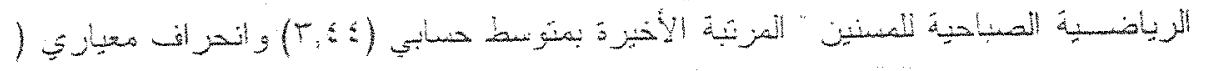

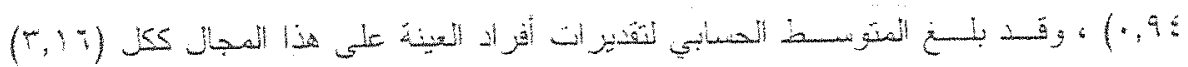

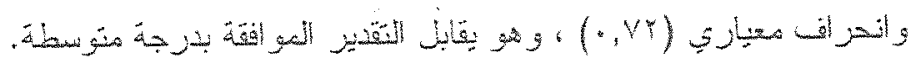

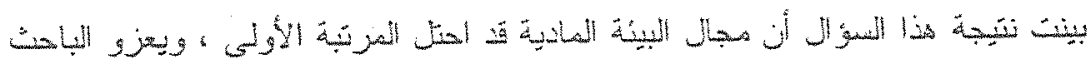

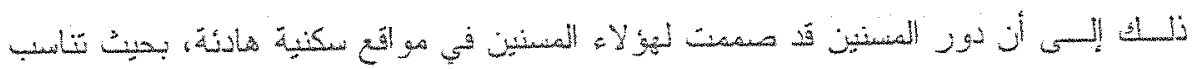

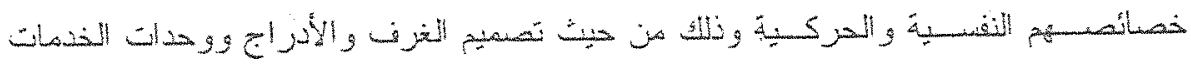

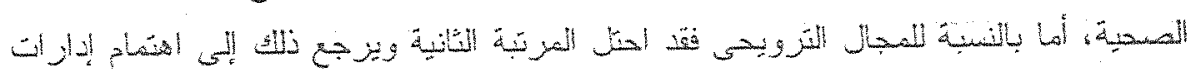

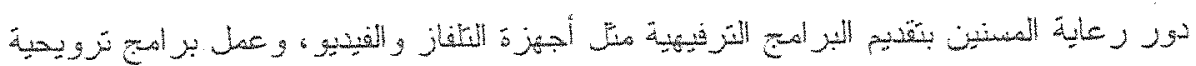

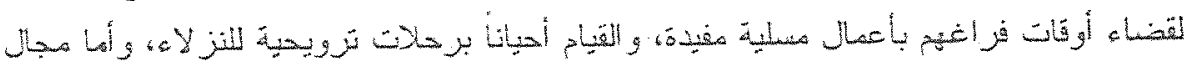

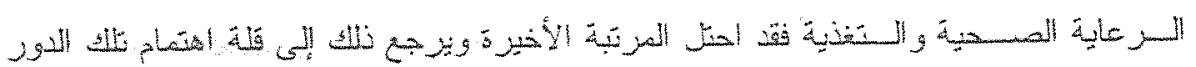

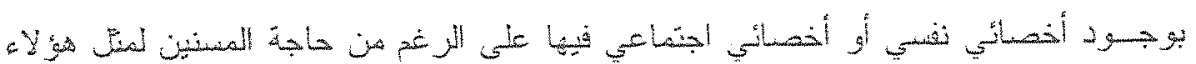
الأخصائيبن. 


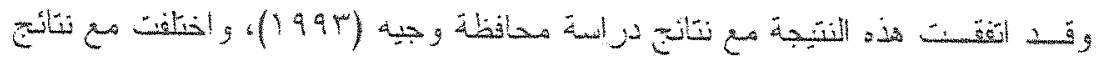

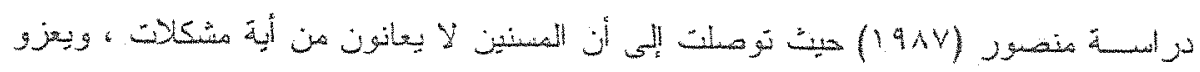

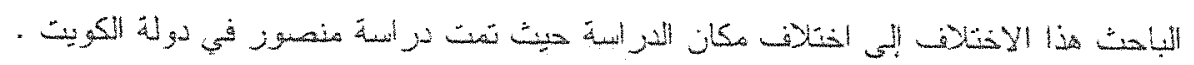

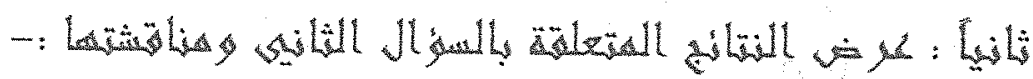

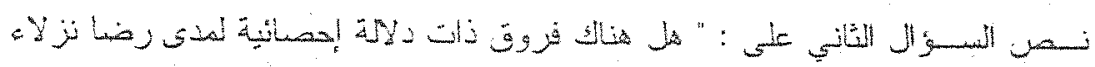

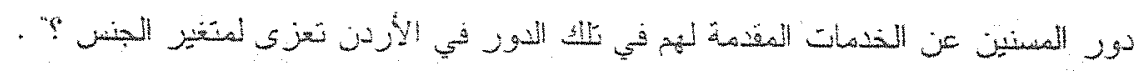

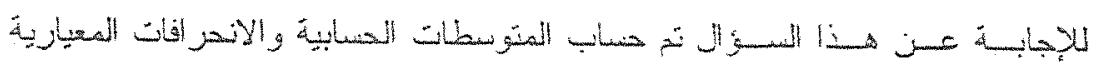

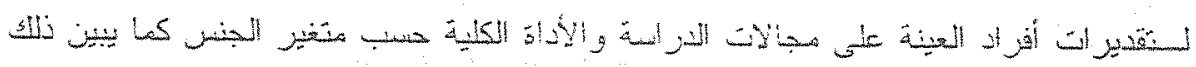
(v)

\section{(V) 303}

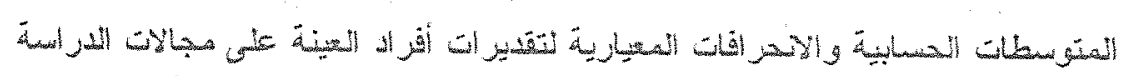

\begin{tabular}{|c|c|c|c|c|c|}
\hline 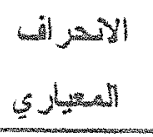 & 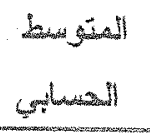 & awath & in & Hosil & 覀 \\
\hline$\cdot, r Y$ & 5,10 & $r$ & S & \multirow{2}{*}{ 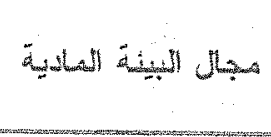 } & \multirow{2}{*}{1} \\
\hline., 54 & 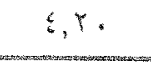 & iv & أُنْتِ & & \\
\hline., 19 & T.AT & +1 & ت & \multirow{2}{*}{ 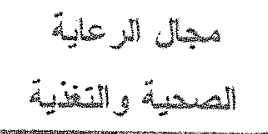 } & \multirow{2}{*}{$\gamma$} \\
\hline$\cdot r . r$ & $Y, A Y$ & $i v$ & أنَثى & & \\
\hline.,$Y+$ & r.IV & $r$ & S & \multirow{2}{*}{ 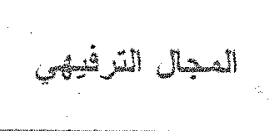 } & \multirow{2}{*}{$r$} \\
\hline$:, Y A$ & 515 & IV & U & & \\
\hline$\cdot, Y q$ & r. Y & $\leftarrow$ & S & \multirow{2}{*}{ 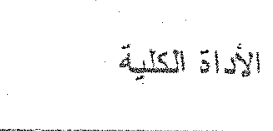 } & \\
\hline .44 & r.Y & W & أنش & & \\
\hline
\end{tabular}

等 هج

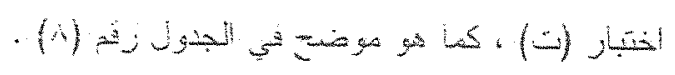




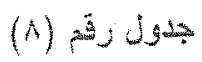

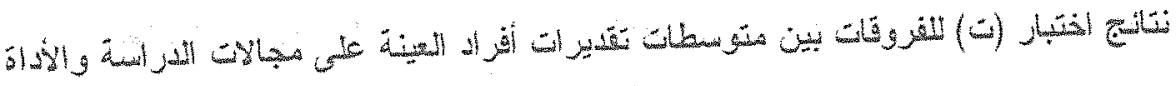

\begin{tabular}{|c|c|c|c|c|c|c|}
\hline 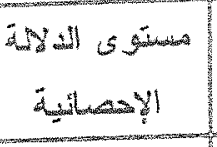 & 3 & 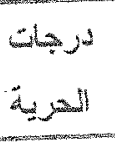 & 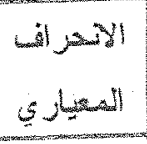 & 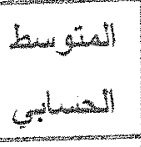 & 残 & ألمبال \\
\hline \multirow{2}{*}{$=, V)$} & \multirow{2}{*}{$\therefore, r$} & \multirow{2}{*}{$\$$} & $\cdot,+4$ & $\therefore 10$ & 5 & \multirow{2}{*}{ 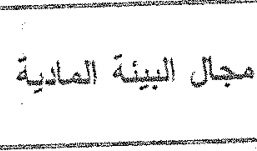 } \\
\hline & & & .4 & 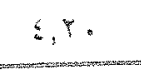 & تَت & \\
\hline \multirow{2}{*}{, YrA } & \multirow{2}{*}{.,$Y 9$} & \multirow{2}{*}{$\leq Y$} & $\because 49$ & $Y, \lambda$ & 5 & \multirow{2}{*}{ 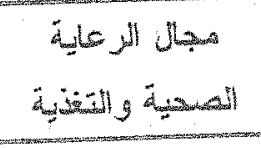 } \\
\hline & & & 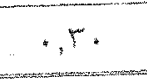 & TAV & 4 & \\
\hline \multirow{2}{*}{$\cdot A Y \leq$} & \multirow{2}{*}{.,$Y T$} & \multirow{2}{*}{$\leqslant v$} &.,$Y 4$ & riv & $S$ & \multirow{2}{*}{ 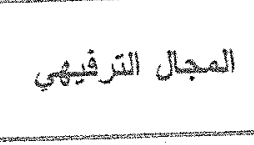 } \\
\hline & & & $\because, Y$ & $\because: 8$ & il & \\
\hline \multirow{2}{*}{$\cdot, y \div 9$} & \multirow{2}{*}{$*, 1$} & \multirow{2}{*}{$\leq Y$} & $\because, Y 9$ & r.T & 5 & \multirow[t]{2}{*}{ 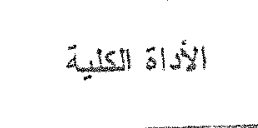 } \\
\hline & & &.+1 & $r, Y i$ & أن & \\
\hline
\end{tabular}

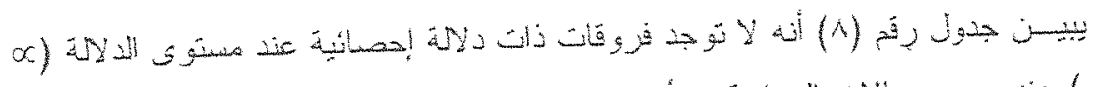

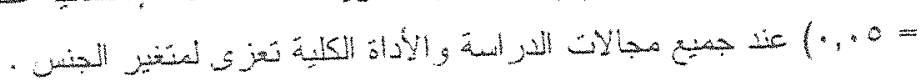

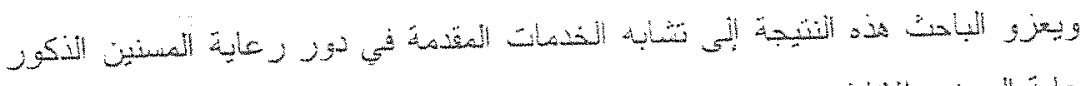

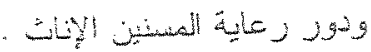

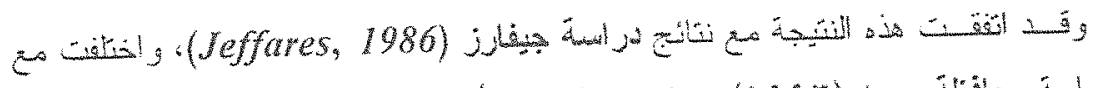

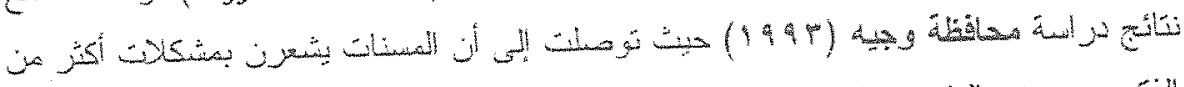

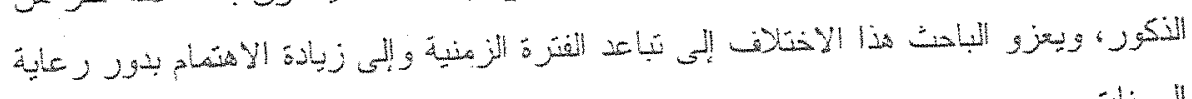
- iniveall

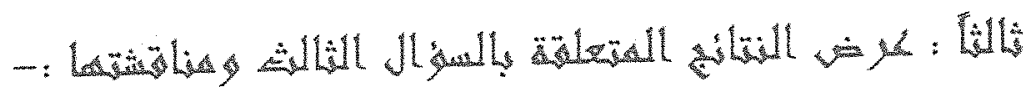

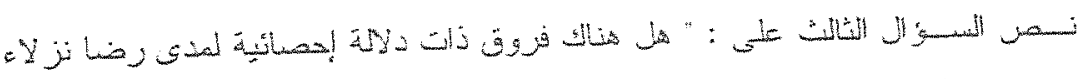

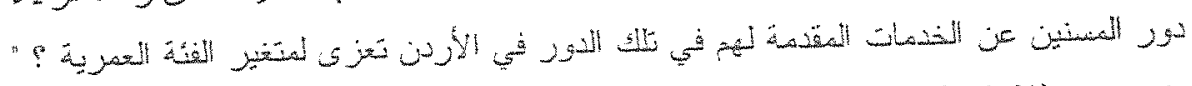

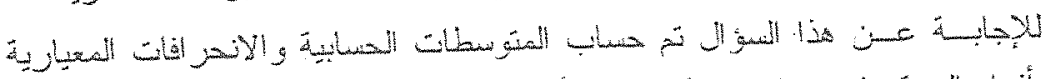

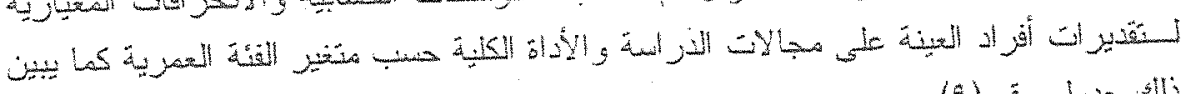
(3) 30 , 
(4) $i^{3}, 0,40$

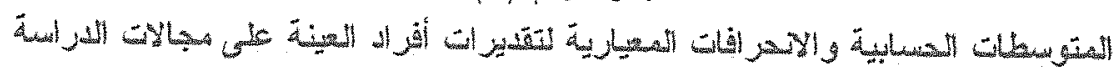

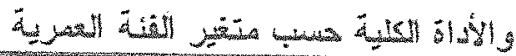

\begin{tabular}{|c|c|c|c|c|}
\hline 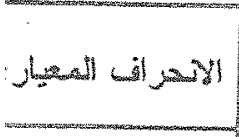 & $\frac{b}{b}$ & 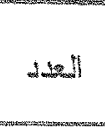 & الثئية المهرية & 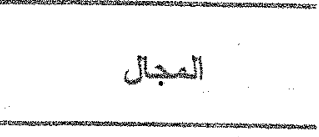 \\
\hline$\because, Y A$ & 5.14 & V & أقزل من من مسية & \\
\hline$\cdot, Y \leq$ & 4,10 & 19 & $\begin{array}{c}\pi-0 . j \\
\end{array}$ & 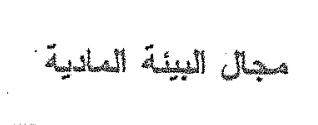 \\
\hline.,$i$ & $E, Y_{Y}$ & $Y Y$ & $\because 3$ is & \\
\hline$\because+$ & $Y, A 0$ & Y & أقلى مز مه نسة & \multirow{3}{*}{ 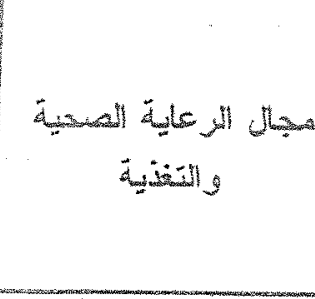 } \\
\hline$\cdot, r r$ & $P, N i$ & 19 & $\begin{array}{c}i \cdot-0 . j \\
\vdots\end{array}$ & \\
\hline$\cdot, r i$ & $Y, A$ & $Y Y$ & $\begin{array}{c}7 \\
0 \\
\end{array}$ & \\
\hline$\because$ & $r, 1:$ & $y$ & 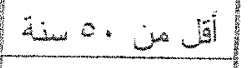 & \multirow{3}{*}{ 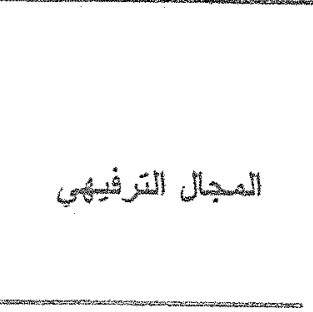 } \\
\hline $0,+4$ &,+ & 19 & $\begin{array}{c}i .0 . j \\
4 \\
\end{array}$ & \\
\hline$\cdot, Y V$ & 5,19 & YY & 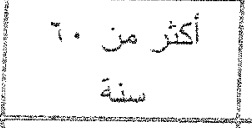 & \\
\hline$\cdot T$ & r, ra & $y$ & 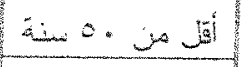 & \multirow{3}{*}{ | } \\
\hline 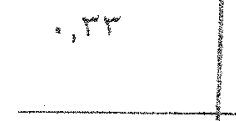 & $r_{1}:=$ & 19 & هن . & \\
\hline YYo & $r, \leq 1$ & $r T$ & 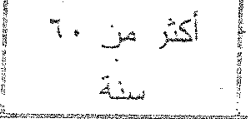 & \\
\hline
\end{tabular}

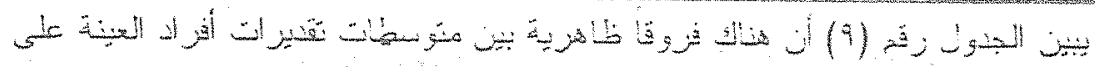

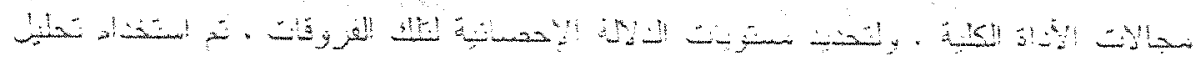

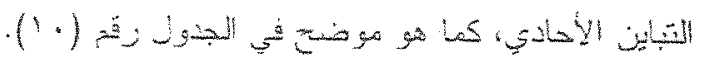


(1.)

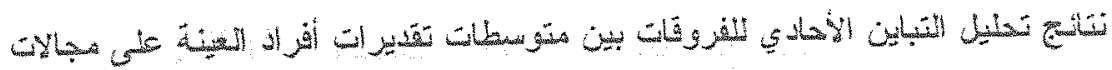

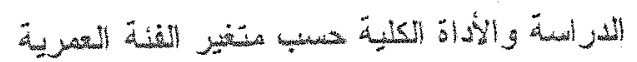

\begin{tabular}{|c|c|c|c|c|c|c|}
\hline الإحسيائية & قئسة فس & الثمرنيتات & النربية & لالمبنهوع & هدسر ألباين & المبجال \\
\hline \multirow{3}{*}{ - } & \multirow{3}{*}{$\cdot, T Y V$} & $.04 \pi$ & $Y$ & UYY & بين المجهو عات & \multirow{3}{*}{ مجلا النبيئة الثمادية } \\
\hline & & 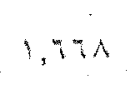 & $\therefore$ & $y o, v y$ & المجهو بات & \\
\hline & & & $8 v$ & $v 5,199$ & إلكي & \\
\hline \multirow{3}{*}{$\cdot, \leqslant \leq n$} & \multirow{3}{*}{ 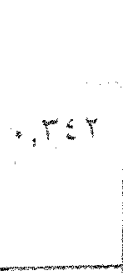 } & $\because 0.6$ & Y & $1, \cdots$ & بين المجهو عات & \multirow{3}{*}{ 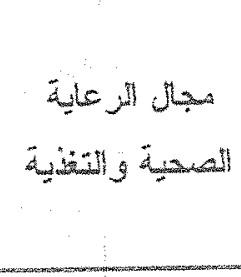 } \\
\hline & & $1,6 V$ & $\therefore 2$ & $\because \because 13$ & المجمو عند & \\
\hline & & & $\leq Y$ & $7 V, 10 \lambda$ & إلكلي & \\
\hline \multirow{3}{*}{$\because A !$} & \multirow{3}{*}{$., 1, r$} & $1,01 Y$ & Y & $r, Y S$ & لبين ألمجسو عات & \multirow{3}{*}{ المجال الثنقيتهي } \\
\hline & & $1, \leq \lambda i$ & $\therefore$ & $Y i, \lambda Y$ & 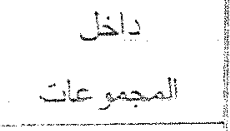 & \\
\hline & & & $\leq Y$ & 79,190 & الكلي & \\
\hline \multirow{3}{*}{ ודיז, } & \multirow{3}{*}{ 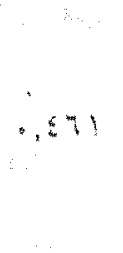 } & $\because, 7.9$ & $r$ & $Y, Y M$ & بين الدجمو عاك & \multirow{3}{*}{ الأساة الكلية } \\
\hline & & Y.HYY & $\therefore 0$ & $09,59 \%$ & لالمجميو تات & \\
\hline & & & $\leqslant V$ & $\because \cdot, y) \leqslant$ & إلكلي & \\
\hline
\end{tabular}

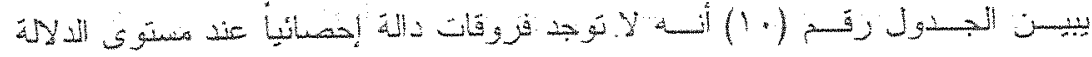

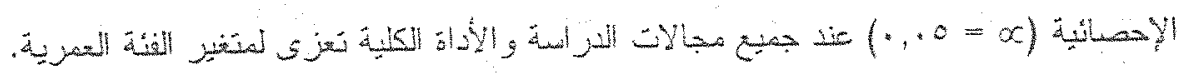

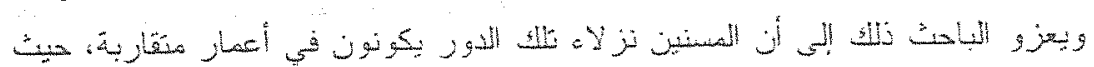

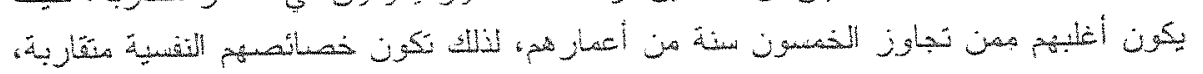

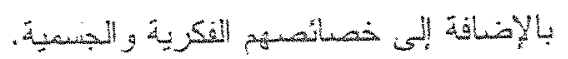

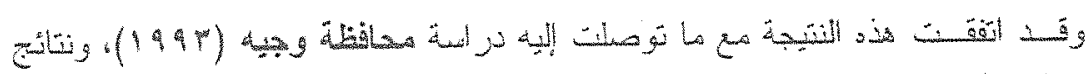

لمرأسة جبيارز (Jeffares, 1986) 



$$
\begin{aligned}
& \text { - sor- } \\
& \text { gell }
\end{aligned}
$$

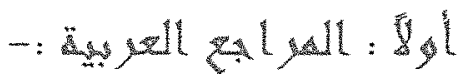

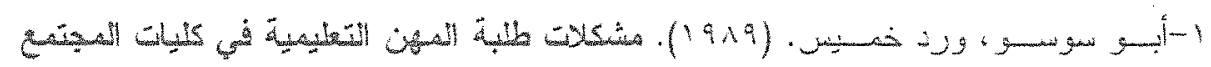

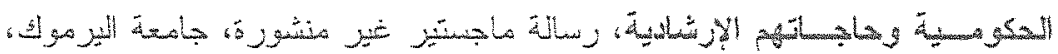

$$
\text { إنبذ: الأزبن. }
$$

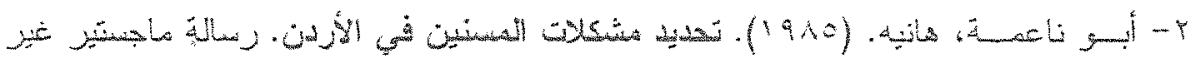

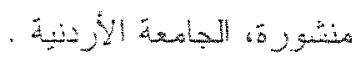

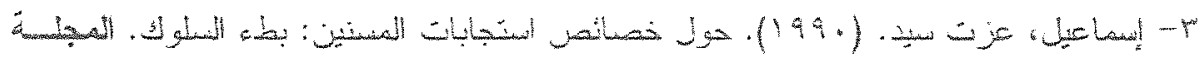

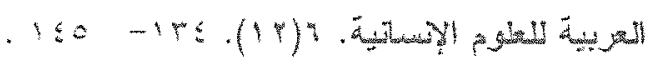

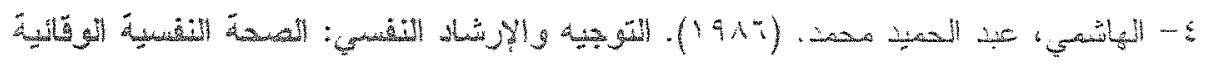

$$
\text { . }
$$

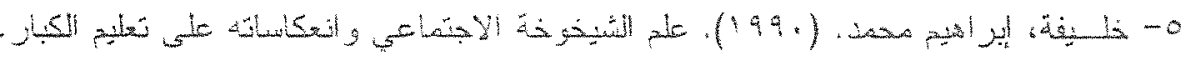

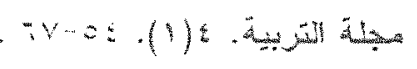

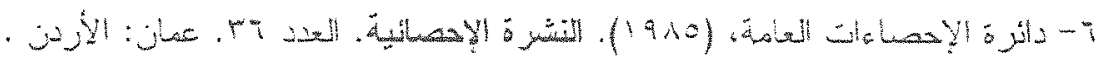

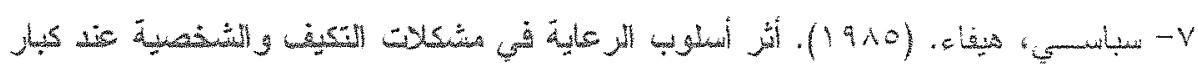

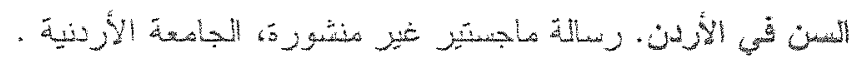

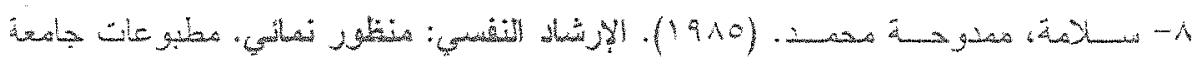

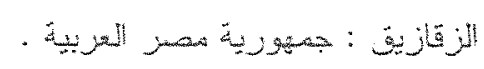

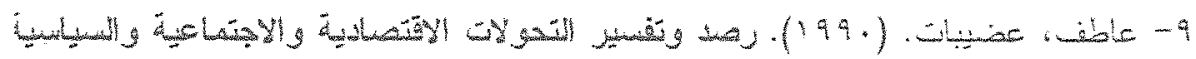

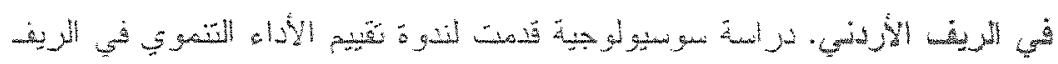

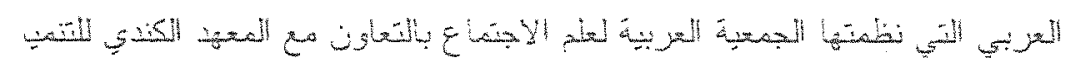

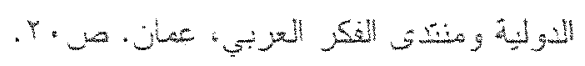

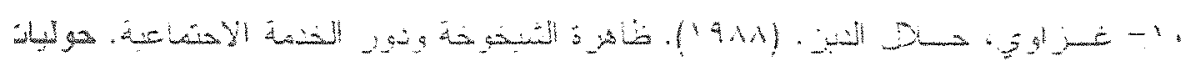

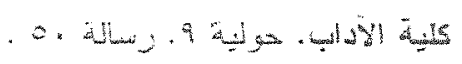

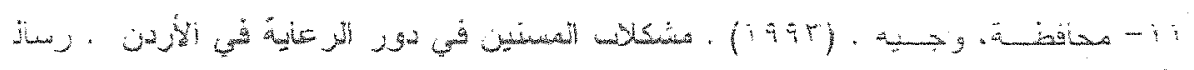

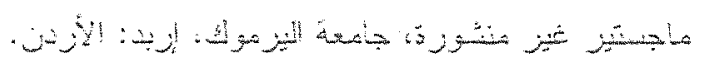




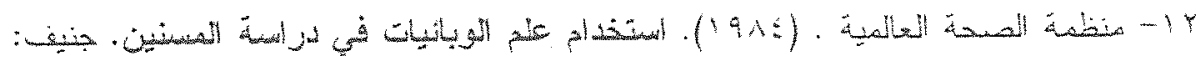
1.

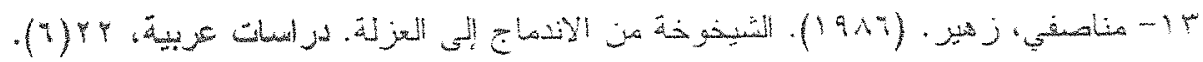
$.1+1 \cdot i$

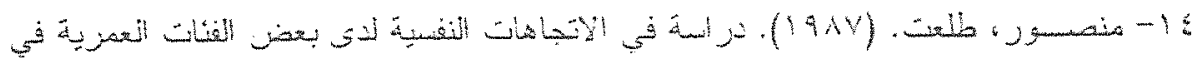

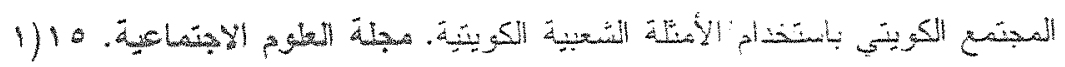
1.19 .9 .1

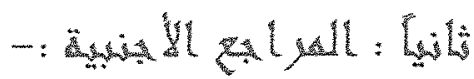

15- Beckinghan. A. C. 1989). A study of self porcened health status and dysphoric mood in an elderly Canadian population. (The Fielding Institute. 1988). Dissertation Abstract International, 50(4). 1052A.

16- Burnside. 1. (1984). Working with the Elderly: Group process and Trchmiques (2ed). Monterey Califonia wad Sworth Health Science Division.

17. Hawis, P. B. (1987). Leadership and qualin of patient care in nursing homes: A path-goal model of leadership (Dotioral Dissertation. Case westem resene University 1987) Dissertation Abstract International, 48(6). 460-A.

18- Jeffares, D. W. (1986). Freedom of choice and its relationship to happiness in a group of new residents in public housing for the elderly. (Doctoral Dissertation. University of Nebraska, Linclon. 1987). Dissertation Abstract Thternational, 47(5).2697-A.

19-Rubio, M. D. H. (1987). Life satisfaction, and locus of control among elderly Iowans. Ilowa State University, 1987). Dissertation Abstract internationa!, 49(2).0351-A.

20-Wexler, M. E. (1988). Residential adjustments of the elderly: $A$ comparison of non-mobile and mobile elderly in Montreal. Dissertation Abstract International, 49(9). 2842-A.

21-White, K. D. (1989). The effect of age on physical functioning and general mental health. (University of Califomia. Los Angeles, 1988).

Dissertation Abstact International, 50(9). 2775-A. 
